\title{
Intoxicação por monofluoroacetato em animais ${ }^{1}$
}

\author{
Vivian Assunção Nogueira ${ }^{2 *}$, Tiago Cunha Peixoto ${ }^{3}$, Ticiana Nascimento França ${ }^{2}$, \\ Saulo Andrade Caldas ${ }^{3}$ e Paulo Vargas Peixoto ${ }^{4}$
}

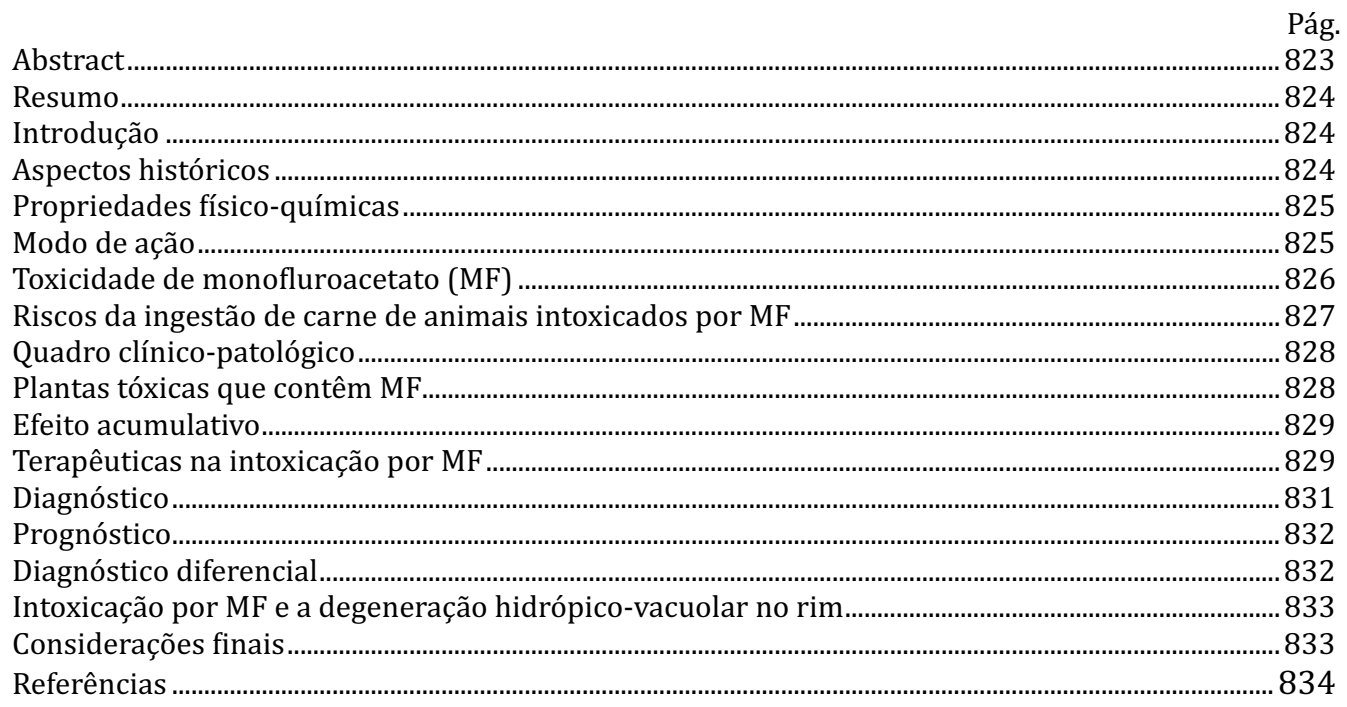

\begin{abstract}
Nogueira V.A., Peixoto T.C., França T.N., Caldas S.A. \& Peixoto P.V. 2011. [Monofluoroacetate poisoning in animals.] Intoxicação por monofluoroacetato em animais. Pesquisa Veterinária Brasileira 31(10):823-838. Projeto Sanidade Animal Embrapa/UFRRJ, Seropédica, RJ 23890-000, Brazil. E-mail: vivianmedvet@yahoo.com.br

Monofluoroacetate (MF) or monofluoroacetic acid is used in Australia and New Zealand for control of native or exotic mammals. The compounds are prohibited in Brazil, as they remain stable for decades and as risk for poisoning of animals and men exists. Cases of criminal and accidental poisonings have been reported in the country. MF was identified in several poisonous plants, the ingestion of which causes "sudden death" in cattle in South Africa, Australia and Brazil. The poisoning leads in the Krebs cycle to the formation of fluorocitrate, its active metabolite, what competitively blocks aconitase in the cycle, with decrease in the production of ATP. Animal species have been classified into four categories regarding the effects caused by MF: (I) on heart, (II) heart and central nervous system, (III) central nertvous system or (IV) with atypical symptoms. In this paper, we present an updated critical review on MF poisoning. The diagnosis is made through the history of ingestion of the poison, by clinical findings and confirmation through toxicological examination. Vacuolarhydropic degeneration of the epithelial cells of the distal convoluted kidney tubules has been considered as characteristic of the poisoning in animal species. The treatment of MF
\end{abstract}

\footnotetext{
${ }^{1}$ Recebido em 12 de janeiro de 2011.

Aceito para publicação em 20 de janeiro de 2011.

Parte da Tese de Doutorado e Dissertação de Mestrado do primeiro e do segundo autor, defendidas na Universidade Federal Rural do Rio de Janeiro (UFRRJ), BR 465, Km 7, Seropédica, RJ 23890-000, Brasil.

${ }^{2}$ Departamento de Epidemiologia e Saúde Pública, Instituto de Veteri-
}

\footnotetext{
nária, Universidade Federal Rural do Rio de Janeiro, Seropédica, RJ. *Autor para correspondência: vivianmedvet@yahoo.com.br

${ }^{3}$ Departamento de Nutrição Animal e Pastagem, Instituto de Zootecnia, UFRRJ, Seropédica, RJ.

${ }^{4}$ Doutorando do Curso de Ciências Veterinárias, Instituto de Veterinária, UFRRJ, Seropédica, RJ.
} 
poisoning is a challenge, since there is still not known any agent that effectively can reverse the poisoning, which generally is fatal.

INDEX TERMS: Monofluoroacetate, poisoning, clinic, pathology, therapeutic, animals.

RESUMO.- O monofluoroacetato (MF) ou ácido monofluoroacético é utilizado na Austrália e Nova Zelândia no controle populacional de mamíferos nativos ou exóticos. 0 uso desse composto é proibido no Brasil, devido ao risco de intoxicação de seres humanos e de animais, uma vez que a substância permanece estável por décadas. No Brasil casos recentes de intoxicação criminosa ou acidental têm sido registrados. MF foi identificado em diversas plantas tóxicas, cuja ingestão determina "morte súbita" de bovinos na África do Sul, Austrália e no Brasil. 0 modo de ação dessa substância baseia-se na formação do fluorocitrato, seu metabólito ativo, que bloqueia competitivamente a aconitase e o ciclo de Krebs, o que reduz produção de ATP. As espécies animais têm sido classificadas nas quatro Categorias em função do efeito provocado por MF: (I) no coração, (II) no sistema nervoso central (III) sobre o coração e sistema nervoso central ou (IV) com sintomatologia atípica. Neste trabalho, apresenta-se uma revisão crítica atualizada sobre essa substância. 0 diagnóstico da intoxicação por MF é realizado pelo histórico de ingestão do tóxico, pelos achados clínicos e confirmado por exame toxicológico. Uma forma peculiar de degeneração hidrópico-vacuolar das células epiteliais dos túbulos uriníferos contorcidos distais tem sido considerada como característica dessa intoxicação em algumas espécies. 0 tratamento da intoxicação por MF é um desafio, pois ainda não se conhece um agente capaz de reverte-la de maneira eficaz; o desfecho geralmente é fatal.

TERMOS DE INDEXAÇÃO: Monofluoroacetato, intoxicação, clínica, patologia, terapêutica, animais.

\section{INTRODUÇÃO}

Embora a comercialização do monofluoroacetato (MF) tenha sido suspensa (Brasil 1997), a intoxicação criminosa por essa substância ainda tem ocorrido no Brasil, dado que esse composto desde que armazenado sob condições adequadas, permanece inalterado por muitas décadas (Eisler 1995).

Outro aspecto significativo relaciona-se ao fato do MF ser considerado por alguns como o princípio tóxico das chamadas plantas brasileiras que causam morte súbita (PBCMS), responsáveis por sérios prejuízos econômicos à pecuária brasileira. Döbereiner \& Tokarnia (1959) verificaram no rim de bovinos intoxicados por Palicourea marcgravii, uma lesão por eles designada degeneração hidrópico-vacuolar (DHV) dos túbulos uriníferos contorcidos distais, que consideram típica para essa intoxicação e de grande valor diagnóstico, em função de sua distribuição peculiar, quase exclusiva a esses túbulos e pela marcada cariopicnose. Mais tarde, verificou-se que tal lesão também aparecia no rim de grande parte dos animais intoxicados com doses únicas de todas as outras onze PBCMS e, em parte menor dos bovinos e ovinos que ingerem frações diárias da dose letal de algumas plantas desse grupo (Tokarnia et al. 2000).

Ambas as hipóteses, porém, vêm sendo há muito ques- tionadas. Estudos recentes, por outro lado, indicam que não só MF é, em última análise, a causa da morte dos animais intoxicados por essas plantas, como também é capaz de induzir uma lesão renal idêntica à observada por Döbereiner \& Tokarnia (1959). (Peixoto et al. 2010, Peixoto et al. 2011c, Nogueira et al. 2010)

No intuito de diminuir dúvidas e aprofundar conhecimentos sobre MF, este trabalho tem como objetivo apresentar e discutir, de forma atualizada e crítica, os aspectos clínicos, toxicológicos, patológicos e patogenéticos mais importantes da intoxicação por essa substância nas diferentes espécies animais.

\section{ASPECTOS HISTÓRICOS}

O monofluoroacetato (MF) foi sintetizado pela primeira vez na Bélgica em 1896 (Chenoweth 1949, Atzert 1971) e patenteado em 1927, como preventivo contra traças (Sayama \& Brunetti 1952). A toxicidade dessa substância foi observada pela primeira vez na Alemanha em 1934 (Atzert 1971). No final dos anos 30 e início dos anos 40, cientistas poloneses estudaram as propriedades tóxicas dos compostos de fluoroacetato, especialmente o ácido fluoroacético de metil éster (Chenoweth 1949). Em 1944, Marais isolou o monofluoroacetato de potássio $\left(\mathrm{CH}_{2} \mathrm{FCOOK}\right)$ de Dichapetalum cymosum, planta da África do Sul reconhecida como tóxica em meados de 1890 (Peacock 1964). Além de D. cymosum, os compostos que contêm fluoroacetato também foram isolados ou identificados por cromatografia gasosa (Oelrichs \& McEwan 1962, McEwan 1964), espectroscopia (Baron et al. 1987) e ressonância magnética nuclear (Krebs et al. 1994, Moraes-Moreau et al. 1995) em outras plantas tóxicas na Austrália (Oxylobium spp., Acacia georginae e Gastrolobium spp.), na África (Dichapetalum toxicarium e D. cymosum) e no Brasil (Palicourea marcgravii, Arrabidaea bilabiata) e, possivelmente, em Mascagnia rigida por cromatografia líquida e em camada delgada (Cunha 2008).

Durante a Segunda Guerra Mundial (1939-1945), devido à falta de rodenticidas como tálio e estricnina, iniciaram-se testes com substâncias alternativas (Eisler 1995). Em junho de 1944, o Departamento de Pesquisa Científica e Desenvolvimento dos Estados Unidos forneceu MF e outros produtos químicos ao Centro de Pesquisa de Animais Selvagens para serem testados como rodenticidas. 0 Centro de Pesquisa deu a MF o número 1080, que subsequentemente foi adotado como nome popular. Amostras da substância também foram enviadas ao Centro de Pesquisa de Animais Selvagens de Denver, EUA, para testes adicionais em outras espécies. Os resultados comprovaram o valor do composto 1080 como controlador eficiente de predadores de animais de produção (Atzert 1971). Ainda durante a Segunda Guerra, MF protegeu tropas aliadas no Pacífico contra roedores (Peacock 1964). Nos EUA foi empregado pela primeira vez 
em 1945 para controle de roedores e, mais tarde, coiotes e coelhos (Hornshaw et al. 1986, Aulerich et al. 1987).

Entre 1946 e 1949, nos EUA, doze pessoas morreram intoxicadas acidentalmente por MF quando este foi utilizado como rodenticida. Neste mesmo período uma criança adoeceu após comer carne cozida de um esquilo intoxicado por MF, mas depois se recuperou (EPA 1976). Desde 1955, essa substância tem sido usada especialmente na Austrália e Nova Zelândia para controlar coelhos europeus (Oryctolagus cuniculus), dingos (Canis familiaris dingo), porcos selvagens (Sus scrofa), marsupiais australianos (Trichosurus vulpecula) e várias espécies de canguru (Mcllroy 1981, 1982a, 1984, Twigg \& King 1991). 0 uso do composto 1080 nos EUA foi proibido em 1972 devido, em parte, às mortes de animais não-alvos (Balcomb et al. 1983); atualmente, a sua utilização nesse país está restrito à proteção de animais de produção (ovinos e caprinos) contra predadores como coiotes (Palmateer 1989, 1990). No Brasil, seu emprego tornou-se restrito a campanhas públicas a partir de 1980, e, em 1982 sua fabricação, comercialização e uso foram proibidos pelo Ministério da Saúde (Adesp 2007). Posteriormente, a sua utilização em produtos rodenticidas domissanitários foi legalmente proibida pela Portaria no. 321, de 28 de Julho de 1997 (Brasil 1997). Segundo Aptekman et al. (2003), cães e gatos são as principais espécies intoxicadas por MF, seja em situações acidentais ou criminosas, e os atendimentos clínicos dos animais com suspeita de intoxicação por esse agente são frequentes. Durante o período de 1999-2003, MF foi responsável por apenas 1,6\% das mortes em cães, causadas por agentes tóxicos no Hospital Veterinário da FMVZ-Unesp, em Botucatu, SP (Xavier et al. 2002).

Em 2004, 73 animais morreram envenenados por MF no Zoológico de São Paulo, entre eles 3 chimpanzés, 3 antas, 5 dromedários, um elefante, um bisão, um orangotango, um macaco-de-cheiro, 2 tamanduás, um sagui-preto-de-mão-amarela, 2 macacos-caiarara, 10 mico-leões-dourados e 43 porcos-espinhos (Ortis 2005).

Em 2005-2009 foram confirmados 17 casos de intoxicação por fluoroacetato de sódio em seres humanos no Estado do Rio Grande do Sul, sem especificar o desfecho (Quadro 1).

\section{PROPRIEDADES FÍSICO-QUÍMICAS}

MF é um derivado do ácido monofluoroacético e, quando encontrado sob a forma de sal de sódio, é cristalino (McGirr \& Papworth 1955), branco, inodoro, insípido (Oliveira 1955, Egekeze \& Oehme 1979), higroscópico quando exposto ao ar, solúvel em água, relativamente insolúvel em solventes orgânicos, tais como querosene, álcool, acetona ou óleos vegetais e animais (Egekeze \& Oehme 1979). É uma substância não-volátil (Oliveira 1955), quimicamente estável (Gribble 1973) à luz solar e à temperatura de 54으 (EPA 1995), devido à forte ligação entre os átomos de carbono e flúor, resiste a temperaturas de até $110^{\circ} \mathrm{C}$ (Eisler 1995) e só se decompõe a partir de $200^{\circ} \mathrm{C}$ (Beasley 2002). Algumas soluções aquosas de MF retêm suas propriedades rodenticidas por pelo menos 12 meses (Eisler 1995). 0 monofluoroacetato de sódio apresenta fórmula molecular $\mathrm{CH}_{2} \mathrm{FCOONa}$ (Fig.1) e massa molecular 100,02g/mol (Beasley 2002).

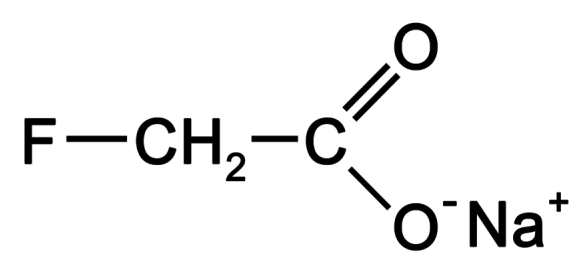

Fig.1. Estrutura química do monofluoroacetato de sódio.

\section{MODO DE AÇÃO}

0 modo de ação de monofluoroacetato (MF) baseia-se na formação do fluorocitrato, seu metabólito ativo, formado no organismo por meio da denominada "síntese letal". 0 fluoroacetato se liga à acetil Coenzima $\mathrm{A}(\mathrm{CoA})$ para formar fluoroacetil CoA, que substitui o acetil CoA no ciclo energético de Krebs e reage com citrato sintase para produzir fluorocitrato. Este composto bloqueia competitivamente a aconitase o que impede a formação das coenzimas NADH e $\mathrm{FADH}_{2} \mathrm{e}$, desta forma, não há transferência de elétrons para a cadeia respiratória e formação de ATP a partir de ADP. Com a queda na produção de ATP, processos metabólicos dependentes de energia são bloqueados. Adicionalmente não há conversão do citrato em isocitrato (Fig.2), e observa-se um acúmulo de citrato em vários tecidos (Buffa \& Peters 1949, Gagnin \& Maravalhas 1969, Clarke 1991). 0 bloqueio do ciclo de Krebs induzido por MF provoca importante redução do metabolismo da energia oxidativa e também diminui a oxidação do acetato e a síntese hepática de acetoacetato. A utilização de acetoacetato nos tecidos é inibida e há acúmulo de ceto-substâncias no sangue, que são excretadas pela urina. Verifica-se também diminuição no uso do piruvato na incorporação de $\mathrm{CO}_{2}$ nos ácidos orgânicos (Novák et al. 1972). Adicionalmente há hipocalcemia, uma vez que o citrato,

Quadro 1. Casos recentes de intoxicação humana por monofluoroacetato de sódio

\begin{tabular}{|c|c|c|c|c|c|c|c|c|c|}
\hline \multirow[t]{2}{*}{ Ano } & \multicolumn{4}{|c|}{ Faixa etária } & \multicolumn{3}{|c|}{ Circunstância da exposição } & \multirow[t]{2}{*}{ Total } & \multirow{2}{*}{$\begin{array}{c}\text { Raticida } \\
\text { NI }\end{array}$} \\
\hline & $<6$ anos & 6-19anos & $>19$ anos & ND & $\begin{array}{c}\text { Não } \\
\text { intencional }\end{array}$ & Intencional & Outros & & \\
\hline 2005 & - & - & 01 & - & - & 01 & - & 01 & 87 \\
\hline 2006 & - & - & 03 & - & 01 & 02 & - & 03 & 70 \\
\hline 2007 & 01 & 01 & 07 & 01 & 01 & 08 & 01 & 10 & 85 \\
\hline $2008 / 2009$ & - & 01 & 02 & - & 01 & 02 & - & 03 & 44 \\
\hline
\end{tabular}

*ND = não determinado, NI = não identificado. Fonte: Nicolella et al. $(2005,2006,2007,2008-2009)$. 


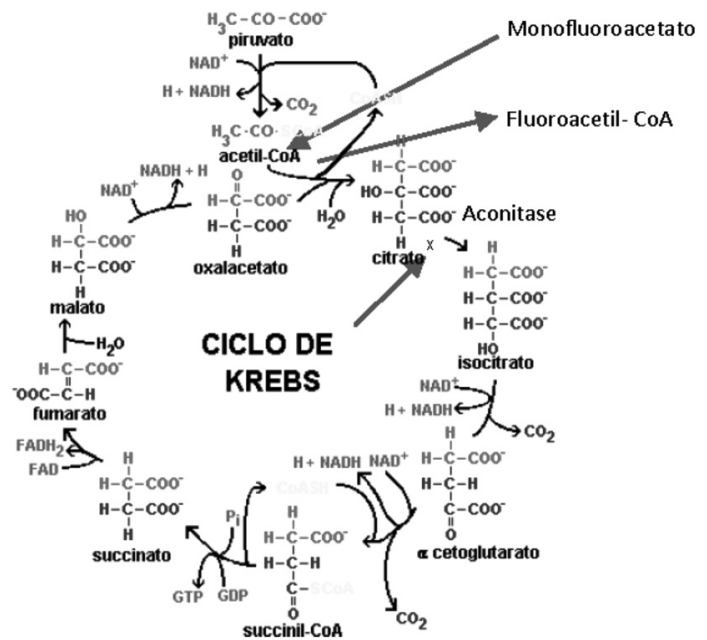

Fig.2. Ação do monofluoroacetato de sódio no ciclo de Krebs.

em concentrações elevadas no organismo, exerce um efeito quelante sobre o cálcio (Eason 2002, Collicchio-Zuanaze et al. 2006). Outras enzimas secundariamente afetadas são succinato desidrogenase (Fanshier et al. 1964), hexoquinase (Bowman 1964), acetil CoA carboxilase, malonil CoA, piruvato carboxilase (Mehlman 1968) e ATP citrato-liase (Rokita \& Walsh 1983). Contudo, ainda não é bem esclarecida a relevância de tais interferências nessas enzimas.

\section{TOXICIDADE DE MONOFLUOROACETATO}

O monofluoroacetato (MF) é altamente tóxico para todas as espécies animais (Humphreys 1988), inclusive para o homem (McTaggart 1970), no entanto os efeitos tóxicos são muito variáveis em função da espécie intoxicada e da sensibilidade individual (Quadro 2) (McIlroy 1981). Além disso, há diferenças significativas no período de latência existente antes do aparecimento dos primeiros sinais clínicos e o intervalo de tempo entre a ingestão de MF e a morte nas diversas espécies de vertebrados. De fato, alguns animais morrem em poucos minutos e outros podem sobreviver por vários dias (Mcllroy 1986), conforme apresentado no Quadro 3.

Os canídeos apresentam maior sensibilidade a essa substância, seguidos por outros carnívoros, herbívoros e aves, já os répteis e anfíbios são os menos sensíveis (Mcllroy 1986). Alguns autores acreditam que tal variação de sensibilidade esta relacionada ao grau de eliminação ou de condensação da substância com o oxaloacetato (Hatch 1987), bem como com a taxa metabólica do organismo, especificamente do metabolismo oxidativo celular, que pode favorecer ou não a metabolização e a eliminação de substâncias tóxicas (Goncharov etal. 2005). A razão exata para essa variação, contudo, ainda não é totalmente compreendida (Goh et al. 2005).

Em relação à sensibilidade individual, observou-se que tanto mamíferos jovens quanto fêmeas de mamíferos aquáticos durante o cio, são mais sensíveis a MF, quando comparados com outros animais da mesma espécie (McIlroy 1981). Outros estudos determinaram que, sob temperaturas elevadas (23-37ํㅡ) os guaxinins (Procyon lotor) são mais sensíveis a
Quadro 2. Doses orais letais do MF para diferentes espécies animais

\begin{tabular}{lc}
\hline Espécie & Dose oral letal $(\mathrm{mg} / \mathrm{kg})$ \\
\hline Cães & $0,06-0,20^{\mathrm{a}}$ \\
Bovinos & $0,15-0,62^{\mathrm{b}}$ \\
Ratos & $0,10-3,0^{\mathrm{c}}$ \\
Ovinos & $0,25-0,50^{\mathrm{b}}$ \\
Caprinos & $0,30-0,70^{\mathrm{b}}$ \\
Gatos & $0,30-0,50^{\mathrm{b}}$ \\
Suínos & $0,30-0,40^{\mathrm{b}}$ \\
Cobaios & $0,5-1,0^{\mathrm{d}}$ \\
Equinos & $0,50-1,75^{\mathrm{b}}$ \\
Camundongos & $0,50-17,0^{\mathrm{c}}$ \\
Coelhos & $0,80^{\mathrm{a}}$ \\
Passeriformes & $2,50^{\mathrm{c}}$ \\
Galinhas & $5,0-7,50^{\mathrm{c}}$ \\
Macacos & $10,0-12,0^{\mathrm{d}}$ \\
Sapos & $150,0(\mathrm{SC})^{\mathrm{c}^{*}}$ \\
Homem & $2,0-10,0^{\mathrm{e}}$ \\
\hline
\end{tabular}

a Parton (2006), 'bumphreys (1988), 'Chenoweth (1949),

dFoss (1948), , eGajdusek \& Luther (1950), "Via subcutânea.

MF do que em temperaturas mais amenas $\left(13-23^{\circ} \mathrm{C}\right.$ ) (Eastland \& Beasom 1986), assim como, camundongos e sapos (Chenoweth 1949), uma vez que a temperatura ambiental altera o metabolismo individual e a sensibilidade a essa substância (Eastland \& Beasom 1986). De fato, Tokarnia et al. (2000) verificaram que o calor ambiental excessivo pode precipitar os sintomas (ou encurtar o período para o aparecimento dos sintomas) no caso de intoxicação por algumas plantas que tenham o ácido monofluoroacético como principio tóxico. Por outro lado, ratos intoxicados experimentalmente com $5,0 \mathrm{mg} / \mathrm{kg}$ de $\mathrm{MF}$, quando submetidos à temperatura ambiental de $23^{\circ}$ e $17^{\circ} \mathrm{C}$ apresentaram comportamento oposto, já que a taxa de mortalidade aumenta de 3\% para 47\%, respectivamente (Misustová et al. 1969). Segundo Buffa \& Pasqualli-Ronchetti (1977), o variável grau de permeabilidade da membrana celular a MF, bem como diferenças morfológicas e funcionais entre grupos celulares podem, de certa forma, justificar a diferença na toxidez da substância para as diversas espécies animais. Entretanto, Eisler (1995) considera que a variação na resposta individual a MF pode ser atribuída à reduzida habilidade em converter o fluoroacetato em fluorocitrato.

MF exerce efeito direto sobre o sistema efetor da termorregulação. $O$ bloqueio específico do ciclo de Krebs provoca uma redução na produção de calor e do metabolismo aeróbico com consequente hipotermia, já observada em gatos (Misustová et al. 1969, Collicchio-Zuanaze et al. 2006) e ratos (Sikulová \& Novák 1970).

Em ratos, foi demonstrado experimentalmente que o acúmulo de citrato é mais acentuado no rim e no fígado (Spencer \& Lowenstein 1967) e, em coelhos, no miocárdio e cérebro (Huang et al. 1980). Outros estudos verificaram que a concentração do citrato no rim aumenta progressivamente da região cortical para a medular (Simonnet et al. 1980) e que, a excreção do citrato acumulado no organismo está diretamente relacionada às condições metabólicas durante 
Quadro 3. Dose oral letal média e progressão da intoxicação por monofluoroacetato em diferentes espécies animais

\begin{tabular}{|c|c|c|c|}
\hline Espécie animal & $\begin{array}{c}\mathrm{LD}_{50} \\
(\mathrm{mg} / \mathrm{kg})\end{array}$ & $\begin{array}{l}\text { Início dos sintomas } \\
\text { após a administra- } \\
\text { ção de MF(h) }\end{array}$ & $\begin{array}{c}\text { Intervalo de tempo } \\
\text { entre a administração } \\
\text { de MF e a morte(h) }\end{array}$ \\
\hline \multicolumn{4}{|l|}{ Mamíferos } \\
\hline \multicolumn{4}{|l|}{ Herbívoros marsupiais } \\
\hline Trichosurus vulpecula (Brushtail possum)* & $0,47-0,79$ & $1,0-19,8$ & $5,0-97,0$ \\
\hline Macropus rufogriseus (Cangurus de Bennett) ${ }^{*}$ & $>0,21$ & $<16,9-23,2$ & $8,9-38,9$ \\
\hline Lasiorhinus latifrons (Southern hairy-nosed wombat) & 0,21 & $5,1-39,4$ & $16,2-59,3$ \\
\hline Macropus giganteus (Eastern grey kangaroo) & $\sim 0,1-0,35$ & $<13,2-23,9$ & $20,9-62,1$ \\
\hline \multicolumn{4}{|l|}{ Herbívoros eutérios } \\
\hline Equus caballus (Equinos) & 1,0 & $\sim 1,5-2,0$ & $6,0-10,5$ \\
\hline Ovis aries (Ovinos) & 0,5 & $6,2-37,6$ & $9,6-61,6$ \\
\hline Oryctolagus cuniculus (Coelhos) ${ }^{*}$ & $0,34-0,5$ & $1,1-10,1$ & $3,0-44,3$ \\
\hline Bos taurus (Bovinos) & 0,39 & $1,5-29,0$ & $1,5-29,3$ \\
\hline \multicolumn{4}{|l|}{ Onivoros/carnívoros marsupiais } \\
\hline Dasyurus hallucatus (“Northern quoll”) & 5,66 & $3,0-361,9$ & $10,0-450,7$ \\
\hline Sarcophilus harrisii (Diabo-da-tasmânia) & 4,24 & $0,3-1,6$ & $2,6-22,3$ \\
\hline Dasyurus viverrinus ("Eastern quoll”) & 3,73 & $0,2-2,24$ & $<2,0-63,2$ \\
\hline Sminthopsis macroura ("Stripe-faced dunnart") & 0,95 & $1,7-4,0$ & $3,4-13,1$ \\
\hline \multicolumn{4}{|l|}{ Onivoros/carnívoros eutérios } \\
\hline Sus scrofa (Porco selvagem) ${ }^{*}$ & 1,0 & $1,9-47,3$ & $2,8-80$ \\
\hline Felis catus (Gatos) ${ }^{*}$ & 0,40 & $1,0-5,6$ & $20,7-21,0$ \\
\hline Canis lupus dingo (Dingo) ${ }^{*}$ & 0,11 & $4,8-14,6$ & $5,3-10,8$ \\
\hline Vulpes vulpes (Raposa-vermelha) ${ }^{*}$ & 0,12 & 4,1 & 5,5 \\
\hline \multicolumn{4}{|l|}{ Roedores } \\
\hline Mus musculus (Camundongo) & 8,33 & $1,3-2,8$ & $2,2-68,3$ \\
\hline Melomys burtoni ("Grassland melomys") & 2,65 & $0,6-1,9$ & $14,1-205,8$ \\
\hline Rattus fuscipes ("Bush Rat") & 1,13 & $0,6-5,1$ & $0,7-24,8$ \\
\hline Rattus rattus (Rato-preto) ${ }^{*}$ & 0,76 & $0,8-27,8$ & $2,4-36,5$ \\
\hline \multicolumn{4}{|l|}{ Répteis e Anfíbios } \\
\hline Tiliqua nigrolutea ("Blotched blue-tongued lizard”) & 336,4 & $13,3-160,9$ & $14,4-68,3$ \\
\hline Pogona vitticeps (Dragão-barbudo) & $<110$ & 15,2 & $14,9-24,2$ \\
\hline Limnodynastes tasmaniensis (Sapo "spotted grass") & $\sim 60$ & $12,9-77,5$ & $36,8-98,3$ \\
\hline Varanus gouldii ("Gould's monitor") & 43,6 & $24,2-141,2$ & $66,5-292,5$ \\
\hline \multicolumn{4}{|l|}{ Aves } \\
\hline Dromaius novaehollandae (Emu) & $\sim 278$ & $1,5-5,8$ & 124 \\
\hline Cacatus galerita (Cacatua-de-crista-amarela) & 3,46 & $9,9-17,7$ & $9,0-73,7$ \\
\hline Gymnorhina tibicen ("Australian magpie) & 9,93 & $3,6-10,7$ & $9,0-73,7$ \\
\hline Aquila audax (Águia "wedge-tailed") & 9,49 & $1,0-60,0$ & $8,0-158,5$ \\
\hline
\end{tabular}

a intoxicação por MF (Grollman et al. 1961). Segundo esses autores, em quadros de acidose e acidificação da urina há uma considerável diminuição da excreção do citrato.

Alguns autores acreditam que as convulsões observadas em intoxicações por MF decorrem do acúmulo de citrato associado à depleção de cálcio ionizado (Buffa \& Peters 1950); porém, outros rejeitam essa hipótese, uma vez que a administração de cálcio endovenoso ou subaracnóideo não impede a ocorrência de crises convulsivas (Bosakowiski \& Levin 1986, Hornfeldt \& Larson 1990). MF atua de forma direta sobre o córtex cerebral, uma vez que a inativação prévia da saída de íons cloro nos neurônios motores causa inibição cortical pós-sináptica da geração do potencial de ação (Raabe 1981). Convulsões induzidas pela hipoglicemia insulínica diferem daquelas provocadas por MF. No primeiro caso, ocorre redução da concentração de glicose para o sistema nervoso central (SNC); já a intoxicação por MF causa o bloqueio específico do ciclo de Krebs e as convulsões são de- correntes do reduzido suprimento energético ao SNC (Marrazzi \& Holliday 1981). Em coelhos, a convulsão e fibrilação ventricular iniciam-se, em geral, após um estímulo externo ou pela contenção dos animais; tal constatação, sugere que o aumento na liberação de catecolaminas durante a intoxicação pode exercer um fator desencadeador das alterações cardíacas nestes animais (Huang et al. 1980).

\section{RISCO DE INGESTÃO DA CARNE DE ANIMAIS INTO- XICADOS POR MF}

0 risco do consumo de carnes ovina e caprina provenientes de áreas que utilizam monofluoroacetato (MF) para o controle de predadores domésticos e também a possibilidade de intoxicação secundária no homem foram avaliados através da presença de resíduos da substância no sangue, músculo, fígado e rins. A meia-vida plasmática de MF foi de 10,8 horas em ovinos e 5,4 horas nos caprinos e as concentrações nos demais órgãos foram inferiores às do plasma e persistiram 
em doses baixas por até 96 horas. Apesar disso, é pouco provável a intoxicação do homem, secundária ao consumo da carne destes animais (Eason et al. 1994).

No Brasil, as observações de Colodel (1999) fornecem uma indicação do eventual risco determinado pela ingestão de vísceras de animais intoxicados por PBCMS: em experimentos para avaliar a toxidez de Palicourea marcgravii, depois da necropsia, a carcaça de um bovino que morreu após receber a dose de $6 \mathrm{~g} / \mathrm{kg}$ da planta, permaneceu ao relento e, 12 horas após, três cães foram encontrados mortos em torno do cadaver. Essa intoxicação indireta é possível, quando a espécie animal que ingeriu vísceras de herbívoro intoxicado por doses elevadas de PBCMS for sensível ao princípio tóxico.

A concentração de MF nos músculos esqueléticos, rins e fígado de coelhos foi significativamente menor do que no plasma. Esta concentração e a retenção de MF nos tecidos diminuem substancialmente com o tempo após a putrefação das carcaças. A intoxicação de cães pela ingestão do fígado é possível devido à sua extrema sensibilidade ao tóxico, mas pouco provável em aves, que são mais resistentes (Gooneratne et al. 1995).

\section{QUADRO CLÍNICO-PATOLÓGICO}

Tradicionalmente, as diferentes espécies animais são classificadas em Categorias I a IV, em função do efeito provocado por monofluoroacetato (MF). Esse sistema de classificação foi elaborado em 1946 por Chenoweth \& Gilman. Somos da opinião que essa classificação deve ser revista e complementada com os dados recentemente disponíveis. Por exemplo, Chenoweth \& Gilman (1946) não realizaram experimentos com bovinos e ovinos, e, portanto, não agruparam essas espécies em nenhuma categoria. A nosso ver, tais espécies devem ser incluídas na Categoria I, uma vez que o principal efeito de MF em bovinos (Schnautz 1949, Robison 1970, Nogueira et al. 2010) e ovinos (Jensen et al. 1948, Annison et al. 1960, Schultz et al. 1982, Peixoto et al. 2010) se faz sobre o coração.

Em relação aos equinos, Chenoweth \& Gilman (1946) incluíram essa espécie na Categoria I, no entanto, afirmaram ser difícil determinar se havia, de fato, ausência de sintomas nervosos, uma vez que os animais foram anestesiados. Anos depois, outros autores descreveram sintomas referentes também ao SNC (Egekeze \& Oehme 1979). Desta forma, acreditamos que essa espécie deva ser incluída na Categoria II.

Já os ratos e hamsters foram agrupados na Categoria IV, ou seja, animais que apresentam sintomatologia atípica, caracterizada por fraqueza e extrema bradicardia (Chenoweth \& Gilman 1946). Entretanto, esses sinais clínicos foram observados, no dia seguinte à administração do MF, em animais que sobreviveram e, a nosso ver, não deveriam ter sido tão valorizados. Controversamente, esses autores também descreveram sintomas iniciais caracterizados por tremores, alteração postural, hiperexcitabilidade e convulsões tônicas provocadas por estímulos mecânicos. De fato, estudos posteriores demonstraram que ratos intoxicados por esse composto apresentam típica sintomatologia nervosa, caracterizada, em especial, por frequentes convulsões (Foss 1948, Egekeze \& Oehme 1979, Cunha 2008). Além disso, Foss (1948) observou que ratos e camundongos intoxicados por MF apresentavam sinais clínicos nervosos idênticos aos manifestados por cobaios. Convém lembrar que Chenoweth \& Gilman (1946) verificaram que cobaios apresentam alterações nervosas semelhantes àquelas descritas em cães e, desta forma, são incluídos na Categoria III. Contudo, somos da opinião que ratos e hamsters pertencem à Categoria III. Desta forma, fica evidente que algumas complementações e modificações devem ser feitas nesse tradicional sistema de classificação.

A intoxicação por MF no homem produz vômito, agitação, irritabilidade, dor epigástrica, dor de cabeça, náusea, dor muscular, convulsões epileptiformes, paralisia parcial, coma, depressão respiratória, além de falência cardíaca aguda e morte devido à fibrilação ventricular (McTaggart 1970, Reigart et al. 1975, Chung 1984, Chi et al. 1996).

Trabes et al. (1983) relataram um caso de intoxicação aguda como tentativa de suicídio, em uma adolescente de 15 anos de idade. 0 acompanhamento com tomografia computadorizada demonstrou atrofia cerebral difusa, dilatação da cisterna basal, dos ventrículos laterais e do terceiro ventrículo. A paciente apresentou sinais agudos de náuseas, vômitos, dor abdominal, convulsões e coma, e permaneceu com alterações neurológicas de disfunções cerebelares, distúrbios de memória e comportamento depressivo 18 meses após a intoxicação. Em outro caso, houve intoxicação subaguda em um homem, que morreu devido à pneumonia aspirativa. À necropsia observaram-se congestão pulmonar, hepática e renal. 0 exame histopatológico evidenciou miocardite intersticial focal e congestão dos pulmões, fígado e rins (Peters et al. 1981).

A avaliação eletrocardiográfica no homem mostra alterações inespecíficas do segmento ST e anormalidades na onda T. Adicionalmente verificam-se hipocalcemia e hipocalemia (Peters et al. 1981, Chi et al. 1996, 1999). Manifestações clínicas neurológicas como convulsões tônico-clônicas, hiperexcitabilidade e desorientação (Peters et al. 1981, Robinson et al. 2002), além de insuficiência renal aguda oligúrica ou não-oligúrica (Chung 1984) também já foram descritas.

Com relação aos achados microscópicos, a administração do MF em doses únicas a bovinos e em doses únicas e frações diárias da dose letal aos ovinos determina o aparecimento da degeneração hidrópico-vacuolar (DHV) dos túbulos uriníferos contornados distais associada à cariopicnose (Peixoto et al. 2010, Peixoto et al. 2011c, Nogueira et al. 2010) lesão idêntica à descrita por Döbereiner \& Tokarnia (1959) no rim de bovinos intoxicados com doses únicas de Palicourea marcgravii e, mais tarde observada também no rim de bovinos intoxicados natural e experimentalmente com todas as outras plantas brasileiras que causam "morte súbita" (Tokarnia et al. 2000, Barbosa et al. 2003, Oliveira et al. 2004, Helayel et al. 2009), bem como em ovinos (Tokarnia et al. 1986, Consorte et al. 1994), caprinos (Tokarnia et al. 1993) e em coelhos (Peixoto et al. 1987, Helayel et al. 2009) intoxicados experimentalmente por plantas desse grupo. 


\section{PLANTAS TÓXICAS QUE CONTÊM MONOFLUOROACETATO}

0 monofluoroacetato (MF) foi isolado de diversas plantas na África do Sul (Marais 1944, Vickery \& Vickery 1973), Austrália (Oelrichs \& McEwan 1962, Baron et al. 1987) e Brasil (Oliveira 1963, Krebs et al. 1994, Moraes-Moreau et al. 1995, Cunha 2008), cuja ingestão determina a morte com evolução superaguda em bovinos. Há ainda, fortes indícios de que essa substância também seja o princípio ativo das outras plantas tóxicas brasileiras que também determinam a chamada "síndrome da morte súbita" Acredita-se que, pelo menos 600.000 bovinos, morrem anualmente no Brasil intoxicados por essas plantas (Tokarnia 2010). No Brasil, MF foi identificado por cromatografia em camada delgada (CCD) nas folhas de Palicourea marcgravii (Oliveira 1963, Moraes-Moreau et al. 1995) e, através de espectroscopia por ressonância magnética nuclear flúor ${ }^{19}\left(\mathrm{RMN}^{19} \mathrm{~F}\right)$ tanto em $P$. marcgravii (Krebs et al. 1994, Moraes-Moreau et al. 1995), quanto em Arrabidaea bilabiata (Krebs et al. 1994). Cunha (2008) tentou identificar o MF em extratos de Mascagnia rigida através de CCD e CLAE e detectou a presença de pico cromatográfico com tempo similar ao observado para MF, entretanto, ressalta que "paira a dúvida se realmente o pico observado confirma, de forma definitiva, a presença de fluoroacetato no extrato da planta", uma vez que segundo a autora "por esta técnica não pode ser descartada a presença de interferentes com tempo de retenção similar".

$\mathrm{Na}$ África do Sul, esse composto foi isolado e identificado por Marais (1944) em Dichapetalum cymosum e, posteriormente, em diversas outras espécies de plantas desse gênero (Vickery \& Vickery 1973). Na Austrália, outros autores identificaram MF por cromatografia gasosa e por espectroscopia infra-vermelha em Acacia georginae (Oelrichs \& McEwan 1962) e Gastrolobium grandiflorum (McEwan 1964). Estudos posteriores detectaram e quantificaram MF por espectroscopia de $\mathrm{RMN}^{19} \mathrm{~F}$ em Oxylobium spp., Acacia georginae e Gastrolobium spp. (Baron et al. 1987). Embora ainda não tenham sido desenvolvidos estudos com a finalidade de detectar a possível presença de MF nas outras nove PBCMS, Palicourea grandiflora, P. juruana, P. aeneofusca, Arrabidaea japurensis, Pseudocalymma elegans, Mascagnia elegans, M. pubiflora, M. exotropica (M. amorimia) e M. aff. rigida, é provável que esse composto também seja o principio tóxico determinante dos sinais clínicos e da morte dos animais intoxicados por essas plantas.

\section{EFEITO ACUMULATIVO}

0 efeito acumulativo do monofluoroacetato (MF) é um fenômeno intimamente associado à amplitude do intervalo de tempo entre as administrações e a espécie em questão (Cheno-weth 1949, Atzert 1971). De fato, a administração diária de $1 / 4$ da $L_{50}$ de $M F$ a cães domésticos resulta em convulsões e morte dos animaisl após a quinta dose. Por outro lado, doses subletais maiores podem ser administradas a cães em dias alternados ou em intervalos maiores, sem o desenvolvimento de efeitos adversos (Foss 1948). Posteriormente, verificaram-se também em ovinos que a administração de MF, por via endovenosa, nas doses de $0,25 \mathrm{mg} / \mathrm{kg}$ e
$0,1 \mathrm{mg} / \mathrm{kg}$ repetidas a cada três dias, provocam sintomas e a morte dos animais, entretanto, quando o intervalo de tempo entre as administrações é aumentado, os animais manifestam apenas sintomas leves (Annison et al. 1960). Rowley (1963) comprovou através de experimentação que repetidas doses subletais de MF também podem acumular e causar a morte de coelhos silvestres. Outros autores demonstraram que doses de $0,05 \mathrm{mg} / \mathrm{kg} /$ dia de $\mathrm{MF}$ administradas via fístula ruminal, provocam a morte de ovinos em até três semanas (Jarrett \& Packham 1956).

Outro achado interessante se refere à espécie envolvida. Foi verificado que a administração de subdoses a algumas espécies animais como águias, ratos, camundongos e macacos resulta no desenvolvimento de tolerância. Por outro lado, em cães, cobaios, coelhos e patos selvagens, a administração de doses subletais repetidas ocasiona acúmulo de níveis letais de MF (Atzert 1971).

\section{TERAPÊUTICA DA INTOXICAÇÃO POR MONOFLUOROACETATO}

Embora os mecanismos de toxicidade do monofluoroacetato (MF) já tenham sido suficientemente estudados e compreendidos há mais de quatro décadas, ainda não foram desenvolvidos, até o momento, protocolos terapêuticos eficientes no tratamento da intoxicação por MF (Proudfoot et al. 2006). 0 tratamento da intoxicação por MF é um desafio para os médicos e veterinários (Goh et al. 2005), uma vez que o desfecho dessa intoxicação é quase sempre fatal (Burger \& Flecknell 1994).

0 tratamento da intoxicação por MF consiste basicamente em desintoxicação, terapias de suporte e específica, com a administração de antídoto. Como tentativas de desintoxicação, em geral, são realizadas a indução à êmese e lavagem gástrica, quando o animal não vomitou, e administração de adsorventes como o carvão ativado, colestipol ou resinas de troca iônica, que deve ser realizada o mais rápido possível após a ingestão de MF (Osweiler 1996, Norris et al. 2000), entretanto, na literatura são escassos os dados confiáveis acerca da eficácia desse método (Goh et al. 2005). Em ratos (Wickstrom et al. 1998), diferentemente do que ocorre em cães (Goh et al. 2005), o colestipol reduz a 50\% a concentração sérica de MF durante as primeiras quatro horas após a intoxicação (Wickstrom et al. 1998) e reduz a mortalidade dos ratos, quando administrado 30 minutos após a exposição ao MF (Norris et al. 2000). Contudo, quando são administradas altas doses de MF, tanto o carvão ativado como o colestipol, não são capazes de reduzir a absorção de MF de forma suficiente para proteger os ratos do óbito. Em cães, a utilização de diálise peritoneal, embora recupere quantidade substancial do MF, não é eficaz na redução da concentração sanguínea dessa substância (Wickstrom et al. 1998). Na terapia de suporte, são utilizadas medicações que controlam as convulsões, com auxílio da intubação e ventilação (Osweiler 1996).

Uma grande variedade de potenciais antídotos têm sido estudada, em especial, em ratos e camundongos, incluindo o monoacetato de glicerol (Rammell \& Livingstone 1985), 
acetamida (Egyed \& Schultz 1986, Górniak et al. 1994), sais de cálcio (Shapira et al. 1980), gluconato de cálcio associado ao a-cetoglutarato de sódio e succinato de sódio (Omara \& Sisodia 1990), bicarbonato de sódio (Churchill 1996), agentes moduladores de neurotransmissores (Cook et al. 2001) e 4-metilpirazole (Feldwick et al. 1997).

Com base no mecanismo de ação de MF, acredita-se que compostos precursores de acetato (referidos como "doadores de acetato") sejam capazes de reduzir a inibição competitiva de MF pelo mesmo sítio ativo (Coenzima A) (Pattison 1959). Como consequência, tais compostos exerceriam efeito protetor nas intoxicações por MF, por impedirem ou reduzirem a ocorrência da chamada "síntese letal" (terapia específica) (Egyed \& Schultz 1986).

0 monoacetato de glicerol é considerado o agente protetor mais eficaz em casos de intoxicação por fluoroacetato em ratos, coelhos, cães e macacos Rhesus (Chenoweth et al. 1951, Rammell \& Livingstone 1985), quando administrado precocemente, na dose de $0,5 \mathrm{mg} / \mathrm{kg} /$ hora, por via intravenosa ou intramuscular até 20 minutos após a intoxicação (Mount 1992).

Em 1982, a Organização Mundial de Saúde (OMS) recomendou o uso do monoacetato de glicerol na dose de $0,5 \mathrm{mg} /$ $\mathrm{kg}$, por via intramuscular (i.m.) a cada 30 minutos por 12 horas (Ramell \& Livingstone 1985). Outro protocolo descrito para o homem é baseado em estudos realizados em macacos (Chenoweth et al. 1951) e consiste na administração de 0,1-0,5mL de solução $60 \%$ de monoacetato de glicerol $/ \mathrm{kg}$, diluída à uma concentração de $<1 \%$, antes da administração por via intravenosa. Alguns autores recomendam para cães doses de $2-4 \mathrm{mg} / \mathrm{kg} / \mathrm{hora} / \mathrm{i} . \mathrm{m}$. (Kirk 1980) ou inicialmente $0,5 \mathrm{~mL} / \mathrm{kg} / \mathrm{i} . \mathrm{m}$., e doses seguintes de $0,2 \mathrm{~mL} / \mathrm{kg} / \mathrm{i} . \mathrm{m}$. a cada 30 minutos por 5 horas (Ramell \& Livingstone 1985).

A oxidação de etanol leva ao aumento da concentração sanguínea de acetato e consequente inibição da produção de fluorocitrato. A mortalidade de ratos, cobaios e coelhos intoxicados é significativamente reduzida através da administração de $800 \mathrm{mg} / \mathrm{kg}$ de solução de etanol a $10 \%$, por via subcutânea, em até 30 minutos após a exposição a MF. O efeito protetor mais marcante foi observado em camundongos, quando o etanol foi fornecido 10 minutos após a intoxicação. Por outro lado, em cães, esse efeito não é observado (Hutchens et al. 1949). Outra opção é administrar $8,8 \mathrm{~mL} / \mathrm{kg}$ de solução de $1: 1$ de etanol a $50 \%$, por via oral, associado ao ácido acético a $5 \%$, embora seja menos eficaz que o Monoacetinò (Palermo-Neto \& Moraes-Moreau 1995). Em ratos (Tourtellote \& Coon 1949) e em camundongos (Chenoweth 1949) foi demonstrado experimentalmente que o acetato de sódio e o etanol, quando administrado juntos, possuem efeito sinérgico protetor na intoxicação por MF (Chenoweth 1949, Tourtellote \& Coon 1949). Em macacos, a administração de $2,0 \mathrm{~g} / \mathrm{kg}$ de acetato de sódio associada a $2,0 \mathrm{~g} / \mathrm{kg}$ de etanol é recomendada para o tratamento da intoxicação por MF (Peacock 1964).

Pecuaristas da África do Sul, apesar de desconhecerem o mecanismo de ação desses antídotos, fazem uso de um interessante tratamento popular empírico para reverter a intoxicação por Dichapetalum cymosum (planta da África do Sul que contém MF) em animais de produção, baseado na utilização de partes iguais de vinagre (ácido acético) e cerveja de sorgo (etanol) (Steyn 1934).

Ao avaliar a eficácia da administração de acetamida na intoxicação experimental por MF, bem como por folhas frescas de Palicourea marcgravii ou com extratos concentrados de P. marcgravii, P. juruana, Pseudocalymma elegans, Arrabideaea bilabiata, Mascagnia rigida, M. pubiflora, M. exotropica (M. amorimia) e $M$. aff. rigida, a substância demonstrou acentuado efeito protetor, uma vez que evitou, em todos os experimentos, tanto aparecimento dos sinais clínicos, quanto a morte de todos os ratos intoxicados, com exceção dos animais que receberam extrato concentrado de $M$. rigida (Peixoto et al. 2011b). A administração de acetamida $(2,0 \mathrm{~g} / \mathrm{kg})$ aos bovinos intoxicados com MF $(0,5 \mathrm{mg} / \mathrm{kg})$ e $P$. marcgravii $(1,0 \mathrm{~g} / \mathrm{kg})$ preveniu os sinais clínicos e a morte de todos os animais (Peixoto et al. 2011a).

Em ratos intoxicados por extrato aquoso de $P$. marcgravii $(117,9 \mathrm{mg} / \mathrm{kg})$ e MF $(1,09 \mathrm{mg} / \mathrm{kg})$ verificou-se que a administração de $1,25 \mathrm{~g} / \mathrm{kg}$ de acetamida, por via intraperitoneal, uma hora antes da intoxicação dos animais, em ambos os casos, evitou o desenvolvimento de sinais clínicos e a morte (Górniak et al. 1994).

A eficiência do uso de gluconato de cálcio $(130 \mathrm{mg} / \mathrm{kg})$, á-cetoglutarato $(252 \mathrm{mg} / \mathrm{kg})$ e succinato de sódio $(240 \mathrm{mg} /$ $\mathrm{kg}$ ) como antídotos contra a intoxicação por MF foram avaliados individualmente e associados, em camundongos intoxicados com $15,0 \mathrm{mg} / \mathrm{kg}$ de MF, por via intraperitoneal. Os tratamentos foram realizados 15 minutos a 36 horas após a administração de MF. A administração isolada desses três antídotos, bem como a associação do gluconato de cálcio com o alfa-cetoglutarato foi ineficaz na redução da mortalidade dos animais. No entanto, a administração do succinato de sódio associado ao gluconato de cálcio, 15 minutos após a intoxicação por MF, gerou um forte efeito protetor. Por outro lado, o uso de succinato de sódio em doses elevadas (360-480 mg/kg) associado ao glu conato de cálcio $(130 \mathrm{mg} /$ $\mathrm{kg}$ ) não produz efeito protetor (Omara \& Sisodia 1990) por razões, até então, desconhecidas (Proudfoot et al. 2006). Outros estudos demonstraram que a administração de $5-10 \mathrm{~mL}$ de uma solução a $10 \%$ de gluconato de cálcio, por via endovenosa, previne o desenvolvimento dos quadros tetaniformes, resultantes da acidose láctica (Lloyd 1983). Collicchio-Zuanaze et al. (2006) avaliaram o efeito da administração de succinato de sódio e gluconato de cálcio a $10 \%$, em gatos intoxicados experimentalmente por MF e constataram taxa de sobrevida de $75 \%$ nos animais tratados contra $25 \%$ do grupo controle.

Foi demonstrado que o uso de barbitúricos em cães intoxicados por MF, também possui valor terapêutico, em especial, quando administrados precocemente. Nesse estudo, verificou-se que a administração do barbitúrico $30 \mathrm{~min}$ após a intoxicação por MF, com doses quatro vezes maiores que a $\mathrm{LD}_{50}$ resulta na sobrevida de $80 \%$ dos cães. Por outro lado, quando a terapia é efetuada 3 horas após a intoxicação, a taxa de sobrevida é reduzida consideravelmente (17\%). 
Adicionalmente, foi observado que com altas doses de MF (seis vezes o valor da $L D_{50}$ ), os barbitúricos são ineficazes (Tourtellette \& Coon 1950). Outros autores estudaram o efeito profilático da reserpina na prevenção dos distúrbios cardíacos causados por MF em coelhos. Nesse estudo foram realizadas três administrações prévias de reserpina, com intervalo de quatro horas, por via oral, na dose de $0,25 \mathrm{mg} / \mathrm{kg}$ e, em seguida, os animais receberam $1,5 \mathrm{mg} / \mathrm{kg}$ de MF. A maioria dos animais do grupo tratado com reserpina apresentou prolongamento no tempo de sobrevivência e, alguns animais, se recuperaram completamente. Os autores concluíram que a reserpina preveniu a estimulação adrenérgica de aminas vasoativas, liberadas durante a intoxicação, como mecanismo compensatório para a deficiência do suprimento energético para o coração (Huang et al. 1980).

A administração de $5-10 \mathrm{~mL}$ de solução a $10 \%$ de cloreto de cálcio $\left(\mathrm{CaCl}_{2}\right)$, por via intravenosa lenta e contínua, acompanhada de monitorização previne a taquicardia e a fibrilação ventricular. Tal tratamento tem como finalidade restaurar os níveis de cálcio ionizado que foram supostamente quelados pela elevada concentração do citrato sérico (Palermo-Neto \& Moraes-Moreau 1995).

Foi verificado que a administração de doses elevadas de bicarbonato de sódio, com taxa de infusão contínua $(300 \mathrm{mg} /$ kg durante 15-30 min), causa aumento considerável na taxa de sobrevida de cães expostos a MF, que já manifestam sinais clínicos avançados (Churchill 1996). Segundo outros autores, o bicarbonato de sódio é vital no combate à acidose metabólica observada em casos de intoxicação por MF (Palermo-Neto \& Moraes-Moreau 1995).

Em ratos intoxicados por $P$. marcgravii, o emprego de hidrato de cloral associado à xilazina mostrou-se capaz de prevenir as convulsões e morte e, desta forma, sugeriu-se que essa substância pode atuar como doadora de acetato (Górniak et al. 1993).

Em pesquisa recente, realizada com a finalidade de encontrar um antídoto para MF, foram testadas diversas substâncias em camundongos intoxicados com 15mg/ $\mathrm{kg}$ de MF, por via intraperitoneal. As substâncias foram administradas pela mesma via, 30 minutos após os camundongos terem recebido MF e, incluíram, triacetato de glicerila, acetilmetionina, citrato de sódio, cloridrato de d,1-carnitina, cloreto de magnésio, tiosulfato de magnésio e tiosufalto de sódio, todos na dose de $100 \mathrm{mg} / \mathrm{kg}$, exceto o cloreto de magnésio, cuja a dose foi $50 \mathrm{mg} / \mathrm{kg}$. Verificou-se que a substância com maior atividade antagônica para doses letais de MF foi o tiosulfato de magnésio, uma vez que o seu emprego, evitou a morte de todos os camundongos $(10 / 10)$. Adicionalmente, administraram-se uma solução com $50 \mathrm{~g}$ de tiosulfato de magnésio, por via endovenosa, a um novilho de $300 \mathrm{~kg}$, intoxicado por P. marcgravii e que já manifestava sintomas leves de intoxicação. No dia seguinte, o animal estava completamente recuperado. 0 mecanismo de ação do tiosulfato de magnésio na intoxicação por MF é desconhecido (Pereira \& Pereira 2005).

Outros autores estudaram o valor terapêutico da utilização de agentes moduladores de neurotransmissores na intoxicação por MF em ratos e, verificaram que o uso isolado de agonistas ácido ã-aminobutírico é capaz de controlar apenas alguns sinais clínicos, em especial, as convulsões, embora não aumente a sobrevida dos animais intoxicados. Por outro lado, o uso concomitante de diferentes neuromoduladores aumenta significativamente a sobrevida dos animais (Wickstrom et al. 1998).

Estudos recentes desenvolvidos na Austrália e Nova Zelândia avaliaram os potenciais benefícios da terapia com 4-metilpirazole, um fármaco indicado no tratamento de intoxicação por etilenoglicol, em ratos intoxicados por MF. Esses autores verificaram que a administração de 4-metilpirazole reduz a produção de oxaloacetato através da inibição da enzima malato desidrogenase, o que resulta na redução da produção de fluorocitrato. Embora os sinais clínicos manifestados pelos animais tratados sejam mais leves do que aqueles apresentados pelo grupo controle, não foi verificado redução significativa na concentração sérica de citrato entre os animais experimentais e o grupo controle (Feldwick et al. 1997).

\section{DIAGNÓSTICO}

O diagnóstico da intoxicação por monofluoroacetato (MF) é realizado pelo histórico de ingestão do tóxico, pelos achados clínicos e pela confirmação da presença da substância através do exame toxicológico. A sintomatologia da intoxicação muitas vezes é inespecífica e existem poucos estudos relacionados ao diagnóstico (Chi et al. 1996, 1999, O’Hagan 2004). Na intoxicação aguda por MF, o aparecimento dos sinais clínicos ocorre, em média, 30 minutos a duas horas após a ingestão da substância. As intoxicações subaguda e crônica podem ocorrer principalmente em ruminantes, porém é mais comum em ovelhas, através da ingestão de algumas espécies de plantas tóxicas (Oliver et al. 1979).

0 citrato sérico pode ser investigado como um indicador periférico da presença de compostos que inibem o seu metabolismo, como MF. Em cães e ratos, o aumento dos níveis de citrato sérico está relacionado ao aparecimento e à gravidade dos sinais clínicos. Os níveis de cálcio sérico total são inversamente proporcionais aos níveis de citrato sérico (Bosakowski \& Levin 1986). Egyed (1978) verificou que a elevação dos níveis de citrato nos tecidos pode indicar intoxicação por compostos organofluorados em seres humanos. Porém, na intoxicação por MF em ovelhas, os níveis de citrato no sangue ou tecidos não possuem valor diagnóstico definitivo (Schultz et al. 1982).

Verifica-se ainda aumento nos níveis de glicose e glicogênio séricos, assim como na concentração de amônia no sistema nervoso central. A hiperglicemia pode ser um achado significativo na intoxicação por este composto (Marrazzi \& Holliday 1981). Esta é decorrente do aumento dos níveis de cortisol endógeno, que tem seu metabolismo prejudicado pela diminuição dos níveis de ATP necessários para a metabolização da substância no fígado (Ballard \& Hyde 1967).

O diagnóstico definitivo da intoxicação por MF pode ser realizado por meio da análise toxicológica para identificação da substância. Os métodos qualitativos são os mais comuns e 
foram desenvolvidos principalmente para detecção em iscas líquidas, amostras de solo, sangue, urina, tecidos e plantas tóxicas (Sakai \& Miyahara 1981).

A técnica de cromatografia em camada delgada é utilizada para identificar MF a partir de misturas extraídas de ácido fórmico e fluoreto de sódio para determinações fluorométricas em placas de celulose com a utilização do revelador Azul do Nilo a 0,4\% (Sakai \& Miyahara 1981, McGary \& Meloan 1982).

A análise quantitativa pode ser realizada com técnicas de cromatografia gasosa (CG) e cromatografia líquida de alta eficiência (CLAE) (Kramer 1984, Ozawa \& Tsukioka 1989, Allender 1990, Minnaar et al. 2000, Demarchi et al. 2001, Sporkert et al. 2002, Zeferino et al. 2005). CG foi desenvolvida a partir da determinação de MF como ácido livre em solventes aquosos (Kimball \& Mishalaine 1993). Foi descrito um método bastante sensível por eletroforese de zona capilar, para detecção do MF em iscas (Fuyu et al. 1996).

A determinação de MF em tecidos biológicos e iscas por meio de CG com extração em acetona e água e derivatização com brometo de pentafluorobenzil, demonstrou ser uma técnica de alta sensibilidade com baixos limites de detecção (Allender 1990). Casper et al. (1985) determinaram a quantificação de MF por CG com espectometria de massa e derivatização do extrato das amostras biológicas também em pentafluorobenzil, e a extração foi realizada com a utilização de tungstato de sódio e acetato de etila.

MF também pode ser identificado como ácido livre em solvente aquoso por CG com detector de massa seletivo utilizando colunas capilares de polietilenoglicol (Kimball \& Mishalaine 1993). Em rins, fígado e estômago, a substância foi detectada com a utilização de éster benzil em CG. Ao comparar os métodos de detecção com benzilação ativada por pirólise de sal de amônio quaternário, concluiu-se que os limites foram menores na detecção por foto-ionização, quando comparados ao método de detecção por ionização em chama (Hoogenboom \& Rammell 1987).

Outro método descrito de análise de MF por CG com espectometria de massa, consiste na microextração por meio de amostras acidificadas de carboxi-divinilbenzeno e derivatização com 1-pirenildiazometano, técnica que demonstrou alta sensibilidade com baixos limites de detecção (Sporkert et al. 2002).

CG também pode ser utilizada para determinar a concentração de MF em sangue de coelhos. A extração foi realizada com a utilização de colunas de alumina e a derivatização em acetato de etila, utilizando-se o diclorohexilcarbodiimida como catalisador da reação e 2,4-dicloroanilina como agente da derivação para detecção no cromatógrafo. A purificação do derivado foi realizada com a utilização de acetonitrila e da injeção no cromatógrafo com hexano (Demarchi et al. 2001). Técnicas de CLAE também foram desenvolvidas para determinação quantitativa do MF em amostras biológicas, iscas e para identificação do princípio ativo de Dichapetalum cymosum e Palicourea marcgravii. A substância foi identificada em amostras de plantas tóxicas, fígado bovino e rúmen em CLAE com coluna orgânica de análise ácida à temperatura ambiente, ácido fosfórico como eluente e detecção ultravioleta (Minnaar et al. 2000).
Em amostras biológicas mantidas a temperatura ambiente por 14 dias, houve uma redução de $50 \%$ na capacidade de identificação da substância. Isso ocorreu porque as amostras biológicas que contêm MF devem ser analisadas em até sete dias, se mantidas em temperatura ambiente (Minnaar et al. 2000).

Consideramos a degeneração hidrópico-vacuolar dos túbulos uriníferos contornados distais associada à cariopicnose ser de grande valor no diagnóstico de intoxicação por MF nos animais e que deve ser investigada sempre que houver suspeita de intoxicação por MF (Nogueira et al. 2010, Peixoto et al. 2010, Peixoto 2011c).

\section{PROGNÓSTICO}

Em geral, o prognóstico da intoxicação por MF varia de ruim a grave e depende da quantidade ingerida do tóxico, bem como da gravidade dos sinais clínicos. Contudo, há melhora do prognóstico quando o tratamento com acetamida ou bicarbonato de sódio é instituído precocemente (Parton 2006). Embora no homem, achados como hipotensão, acidose metabólica e aumentado da concentração de creatinina sérica sejam indicadores de mau prognóstico (Chi et al. 1996), em animais não se conhece a relevância de tais alterações no estabelecimento do prognóstico (Goh et al. 2005).

\section{DIAGNÓSTICO DIFERENCIAL}

Diversas enfermidades capazes de induzir à morte súbita de bovinos devem ser consideradas no diagnóstico diferencial. Embora a acentuada deficiência de cobre possa causar morte súbita - a chamada "falling disease"-, animais deficientes nesse elemento apresentam evidente acromotriquia, anemia e, eventualmente outros sintomas. Marcada hemossiderose esplênica e a presença de DHV no rim podem contribuir para a diferenciação entre as duas condições. 0 estabelecimento do diagnóstico diferencial entre intoxicação por monofluoroacetato (MF), carbúnculo hemático e acidente ofídico é fácil e o assunto já foi abordado com profundidade (Tokarnia \& Peixoto, 2006). Intoxicação por plantas cianogênicas também cursa com evolução superaguda e poderia ser confundida com intoxicação por MF; porém, o ácido cianídrico é absorvido rapidamente e os sintomas da intoxicação aparecem logo após ou já durante a ingestão da planta (Clark \& Weiss 1952), diferentemente do que ocorre em bovinos intoxicados por MF. Além disso, não há sinais de insuficiência cardíaca e o exame microscópico não revela lesão significativa.

0 diagnóstico diferencial entre a intoxicação por MF e plantas que causam "morte súbita", deve ser realizado, sobretudo, com base nos dados epidemiológicos, uma vez que não há quaisquer diferenças clínico-patológicas entre essas duas condições. Devemos lembrar, entretanto que, ao contrário do que ocorre em bovinos, a intoxicação de ovinos por plantas desse grupo, sob condições naturais, é pouco comum nessa espécie. São descritos apenas alguns surtos de intoxicação por Mascagnia rigida na Paraíba (Vasconcelos et al. 2008) e por M. exotropica (M. amorimia) no Rio Grande do Sul (Bandarra et al. 2007). Embora a intoxicação 
Quadro 4. Número de animais necropsiados logo após a morte que desenvolveram a degeneração hidrópico-vacuolar (DHV) no rim quando intoxicados experimentalmente por plantas que causam morte súbita

\begin{tabular}{|c|c|c|c|c|}
\hline Animal & Planta & $\begin{array}{l}\text { № total } \\
\text { de animais }\end{array}$ & $\begin{array}{c}\text { № de animais necro- } \\
\text { psiados imediatamente } \\
\text { após a morte }\end{array}$ & $\begin{array}{l}\text { № de animais } \\
\text { com DHV }\end{array}$ \\
\hline \multirow[t]{11}{*}{ Bovino } & Palicourea marcgravii a,b,c,d & 41 & 22 & 16 \\
\hline & Palicourea aeneofusca & 3 & 2 & 1 \\
\hline & Palicourea juruana ${ }^{\mathrm{f}, \mathrm{g}}$ & 10 & 7 & 2 \\
\hline & Palicourea grandiflora ${ }^{\mathrm{h}}$ & 10 & 8 & 4 \\
\hline & Arrabidaea bilabiata ${ }^{\mathrm{i}, \mathrm{j}}$ & 32 & 8 & 2 \\
\hline & Arrabidaea japurensis ${ }^{\mathrm{k}}$ & 11 & 9 & 7 \\
\hline & Pseudocalymma elegans ${ }^{1, \mathrm{~m}}$ & 20 & 9 & 3 \\
\hline & Mascagnia rigida $^{\mathrm{n}}$ & 11 & 7 & 3 \\
\hline & Mascagnia pubiflora ${ }^{\mathrm{o}, \mathrm{p}}$ & 22 & 5 & 3 \\
\hline & Mascagnia aff. rigida ${ }^{\mathrm{q}}$ & 13 & 11 & 5 \\
\hline & M. exotropica (M. amorimia) ${ }^{r}$ & 9 & 3 & 3 \\
\hline \multirow[t]{3}{*}{ Búfalo } & Palicourea juruana $\mathrm{d}^{\mathrm{d}}$ & 4 & 1 & 1 \\
\hline & Palicourea marcgravii ${ }^{\mathrm{d}}$ & 7 & 3 & 1 \\
\hline & Arrabidaea bilabiata $^{\mathrm{j}}$ & 16 & 5 & 0 \\
\hline \multirow[t]{3}{*}{ Ovino } & Palicourea marcgravii s & 32 & 16 & 5 \\
\hline & Mascagnia rigida ${ }^{\mathrm{t}}$ & 6 & 3 & 3 \\
\hline & Pseudocalymma elegans $\mathrm{u}$ & 22 & 9 & 5 \\
\hline \multirow[t]{3}{*}{ Caprino } & Palicourea marcgravii ${ }^{\mathrm{v}}$ & 16 & 7 & 0 \\
\hline & Pseudocalymma elegans $\mathrm{x}$ & 17 & 6 & 3 \\
\hline & Mascagnia rigida ${ }^{\mathrm{t}}$ & 6 & 3 & 3 \\
\hline \multirow[t]{2}{*}{ Equino } & Pseudocalymma elegans ${ }^{\mathrm{z}}$ & 8 & 4 & 3 \\
\hline & Palicourea marcgravii ${ }^{\mathrm{a}^{\prime}}$ & 8 & 4 & 0 \\
\hline \multirow[t]{10}{*}{ Coelho } & Palicourea marcgravii ${ }^{\mathrm{b}^{\prime}}$ & 200 & 116 & 14 \\
\hline & Palicourea grandiflora $\mathrm{c}^{\prime}$ & 11 & 7 & 0 \\
\hline & Palicourea juruana ${ }^{\mathrm{d}}$ & 26 & 14 & 1 \\
\hline & Arrabidaea bilabiata ${ }^{\text {d',e' }}$ & 72 & 37 & 12 \\
\hline & Arrabidaea japurensis ${ }^{\mathrm{f}^{\prime}}$ & 18 & 7 & 6 \\
\hline & Pseudocalymma elegans ${ }^{\mathrm{g}, \mathrm{m}}$ & 6 & 3 & 2 \\
\hline & Mascagnia rigida $\mathrm{h}^{\prime}$ & 24 & 10 & 6 \\
\hline & Mascagnia pubiflora ${ }^{\mathrm{i}^{\prime}}$ & 23 & 4 & 1 \\
\hline & Mascagnia aff rigida ${ }^{\mathrm{j}^{\prime}}$ & 31 & 14 & 7 \\
\hline & Mascagnia exotropica (M. amorimia) & 45 & 14 & 4 \\
\hline Rato & \multicolumn{4}{|c|}{$\begin{array}{l}\text { De acordo com Peixoto et al. (2011a), a interpretação da DHV em ratos é problemática, pois } \\
\text { tende a assemelhar-se, nessa espécie, a alterações autolíticas. Além disso, a lesão clássica é }\end{array}$} \\
\hline
\end{tabular}

\footnotetext{
${ }^{\mathrm{a}}$ Tokarnia \& Döbereiner 1986, böbereiner \& Tokarnia 1959, 'Peixoto et al. 2011b, dBarbosa et al. 2003, ' ${ }^{\mathrm{d}}$ Tokarnia et al. 1983, , Tokarnia \& Döbereiner 1982, goliveira et al. 2004, ${ }^{\text {h}}$ Tokarnia et al. 1981, i Döbereiner et al. 1983, ${ }^{\text {j}}$ Tokarnia et al. 2004, ${ }^{\mathrm{k}}$ Tokarnia \& Döbereiner $1981^{\mathrm{l}}$ Tokarnia et al. 1969, ${ }^{\mathrm{m}}$ Helayel et al. 2009, ${ }^{\mathrm{n}}$ Tokarnia et al. 1961, ${ }^{\circ}$ Santos et al. 1976, ${ }^{\mathrm{p}}$ Tokarnia \& Döbereiner 1973, ${ }^{\mathrm{T}}$ Tokarnia et al. 1985, ${ }^{\mathrm{r}}$ Gava et al. 1998, ${ }^{\mathrm{s}}$ Tokarnia et al. 1986, ${ }^{\mathrm{t}}$ Vasconcelos et al. 2008, "Consorte et al. 1994, vTokarnia et al. 1991, ${ }^{x}$ Tokarnia et al. 1993, ${ }^{\mathrm{z}}$ Tokarnia et al. 1995, a' ${ }^{\text {' }}$ Tokarnia et al. 1993 , b'Peixoto et al. 1987, ${ }^{\prime}$ Döbereiner \& Tokarnia 1982, ${ }^{\prime}$ 'Döbereiner et al. 1984, ${ }^{\prime}$ Jabour et al. 2006, ${ }^{\prime}$ Döbereiner \& Tokarnia 1983, g' Tavares et al. 1974, h'Tokarnia et al. 1987, ,'Döbereiner et al. 1986, i'Tokarnia et al. 1985, k'Tokarnia et al. 1998.
}

criminosa por MF deva ser considerada em casos de morte súbita de ovinos e bovinos, acreditamos que sua ocorrência seria menos provável, pois a comercialização desse composto é proibida no país (Brasil 1997). Contudo, sabe-se que este composto ainda é ilegalmente comercializado por ambulantes (Apevisa 2009) e que, se armazenado sob condições adequadas, a sua toxidez é mantida por décadas (Eisler 1995).

Em cães e gatos, o envenenamento por MF deve ser diferenciado da intoxicação criminosa por outros compostos como carbamato, organofosforado, estricnina e organoclorado (O'Hagan 2004), o que pode ser feito com base nos aspectos clínico-patológicos e, em caso de dúvida, pela análise toxicológica de tecidos desses animais.

\section{INTOXICAÇÃO POR MONOFLUOROACETATO E A DEGENERAÇÃO HIDRÓPICO-VACUOLAR DO RIM}

Embora considere procedente a necessidade de diferenciar a degeneração hidrópico-vacuolar (DHV) dos fenômenos autolíticos que eventualmente ocorrem em túbulos uriníferos, Peixoto et al. (2011c) consideram que as alterações pós-mortais são diferentes e que é possível estabelecer a diferenciação entre as condições com base na morfologia, desde que trata-se de material recém-colhido - autólise avançada inviabiliza qualquer diferenciação: (a) a lesão é extremamente delimitada (afeta somente os túbulos distais); (b) não há sinais de autólise e as células não estão afastadas da membrana basal ("soltas"); e (c) a tumefação é muito mais acentuada de forma que as células afetadas tornam-se pra- 
ticamente vesículas que exibem um núcleo marcadamente picnótico, diferente do que ocorre nos fenômenos autolíticos. Dados sobre o número de animais necropsiados logo após a morte e que desenvolveram a DHV, quando intoxicados experimentalmente por PBCMS, encontram-se no Quadro 4.

\section{CONSIDERAÇÕES FINAIS}

O quadro clínico-patológico da intoxicação pelo monofluoroacetato (MF) envolve diversos sistemas, com consequências clínicas variadas. 0 diagnóstico pode ou não apresentar dificuldades, uma vez que tanto os sintomas, quanto os achados de necropsia podem ser inespecíficos. Desta forma, até hoje, tem sido preconizado, que a confirmação da intoxicação por MF deve ser realizada através de análises toxicológicas que identifiquem esse composto. A nosso ver, a degeneração hidrópico-vacuolar dos túbulos uriníferos contornados distais é de grande valor no diagnóstico para intoxicação por MF nos animais e a sua ocorrência sempre deve ser investigada em casos onde haja a suspeita dessa intoxicação. Assim, como Tokarnia et al. (2000), somos da opinião de que MF é a causa da morte dos animais intoxicados por plantas brasileiras que causam "morte súbita". A terapia da intoxicação por este composto deve basear-se no princípio de que há particularidades nas diferentes espécies animais e extrema variação da sensibilidade individual ao agente tóxico.

\section{REFERÊNCIAS}

Adesp 2007. Associação de Empresas Controladoras de Pragas do Estado de São Paulo. Disponível em <http://www.adesp.org.br> Acesso em 7 jul. 2007.

Allender W.J. 1990. Determination of sodium fluoroacetate (compound 1080) in biological tissues. J. Anal. Toxicol. 14:45-49.

Annison E.F., Hill K.J., Lindsay D.B. \& Peters R.A. 1960. Fluoroacetate poisoning in sheep. J. Comp. Pathol. 70:145-155.

Apevisa 2009. Agência Pernambucana de Vigilância Sanitária. Apevisa apreende 302 frascos com raticida ilegal. Disponível em <http://www. saude.pe.gov.br/noticias.php?codigo $=1066 \&$ pagina $=2 \&$ pu-blicar $=1>$ Acesso em 20 fev. 2009.

Aptekman K.P., Altwegg D., Kitamura E.A., Vicente P.C. \& Sakate M. 2003. Estudo retrospectivo de felinos intoxicados por monofluoroacetato de sódio. Anais $7^{\circ}$ Mostra Científica da FMVZ-Unesp, Botucatu, SP, p.58. (Resumo)

Atzert S.P. 1971. A review of sodium monofluoroacetate its properties, toxicology and use in predator and rodent control. United States Departament of the Interior Fish and Wildlife Services Special Scientific Report, Washington, DC. Wildlife nำ146. 34p.

Aulerich R.J., Ringer R.K. \& Safronoff J. 1987. Primary and secondary toxicity of warfarin, sodium monofluoroacetate, and methyl parathion in mink. Arch. Environ. Contam. Toxicol. 16:357-366.

Balcomb R., Bowen C.A. \& Williamson H.O. 1983. Acute and sublethal effects of 1080 on starlings. Bull. Environ. Contam. Toxicol. 31:692-698.

Ballard C.L. \& Hyde P.M. 1967. Effect of insulin on blood glucose and corticosterone levels in sodium fluoroacetate induced diabetes. Proc. Soc. Exp. Biol. Med. 124:316-320.

Bandarra P.M., Colodel E.M., Raymundo D.L., Pedroso P.M.O., Borba M.R. \& Driemeier D. 2005. Intoxicações em ruminantes por Mascagnia sp. no Rio Grande do Sul diagnosticados no Setor de Patologia Veterinária. XVII Salão de Iniciação Científica, Faculdade de Veterinária, Universidade Federal do Rio Grande do Sul, Porto Alegre, RS.

Barbosa J.D., Oliveira C.M.C., Tokarnia C.H. \& Riet-Correa F. 2003. Compa- ração da sensibilidade de bovinos e búfalos à intoxicação por Palicourea marcgravii (Rubiaceae). Pesq. Vet. Bras. 23(4):167-172.

Baron M.L., Bothroyd C.M., Rogers G.L., Staffa A. \& Rae I.D. 1987. Detection and measurement of fluoroacetate in plant extracts by ${ }^{19} \mathrm{~F}-\mathrm{NMR}$. Phytochem. 26(8):2293-2295.

Beasley M. 2002. Guidelines for the Safe Use of Sodium Fluoroacetate (1080). Occupational Safety and Health Service, New Zealand. 20p.

Bosakowski T. \& Levin A.A. 1986. Serum citrate as a peripheral indicator of fluoroacetate and fluorocitrate toxicity in rats and dogs. Toxicol. Appl. Pharmacol. 85:428-436.

Bowman R.H. 1964. Inhibition of citrate metabolism by sodium fluoro-acetate in the perfused rat heart and the effect on phosphofructokinase activity and glucose utilization. Biochem. J. 93(2):13-15.

Brasil 1997. Normas Gerais para Registro de Desinfetantes Domissanitários. Portaria no 321, de 28 de julho de 1997. Disponível em <http://www. pragas.com.br/legislacao/bancodedados/port321-97.php> Acesso em 15 fev. 2009.

Buffa P. \& Pasquali-Ronchetti I. 1977. Biochemical lesions of respiratory enzymes and configurational changes of mitochondria in vivo. Cell Tiss. Res. 183:1-23.

Buffa P. \& Peters R.A. 1949. Formation of citrate in vivo induced by fluoroacetate poisoning. Nature 163:914.

Buffa P. \& Peters R.A. 1950. The in vivo formation of citrate induced by fluoroacetate poisoning in animals. Fluoride 6:224-247.

Burger I.H. \& Flecknell P.A. 1994. Poisoning, p.656-677. In: Chandler E.A. Gaskell C.J. \& Gaskell R.M. (Eds), Feline Medicine and Therapeutics. $2^{\text {nd }}$ ed. Blackwell, New York.

Casper H.H., McMahon T.L. \& Paulson G.D. 1985. Capillary gas chromatographic-mass spectrometric determination of fluoroacetate residues in animal tissues. J. Assoc. Anal. Chem. 68(4):722-725.

Chenoweth M.B. 1949. Monofluoroacetic acid and related compounds. J. Pharm. Exp. Therap. 1:383-424.

Chenoweth M.B. \& Gilman A. 1946. Studies on the pharmacology of fluoroacetate. 1. Species response to fluoroacetate. J. Pharm. Exp. Therap. 87:90-103.

Chenoweth M.B., Kandel A., Johnson L.B. \& Bennett D.R. 1951. Factors influencing fluoroacetate poisoning. J. Pharm. Exp. Therap. 102:31-49.

Chi C.-H., Chen K.-W., Chan S.-H. Wu M.-H. \& Huang J.-J. 1996. Clinical presentation and prognostic factors in sodium monofluoroacetate intoxication. Clin. Toxicol. 34:707-712.

Chi C.-H., Lin T.-K. \& Chen K.-W. 1999. Hemodynamic abnormalities in sodium monofluoroacetate intoxication. Hum. Exp. Toxicol. 18:351-353.

Chung H.M. 1984. Acute renal failure caused by acute monofluoroacetate poisoning. Vet. Hum. Toxicol. 26:29-32.

Clark R. \& Weiss K.E. 1952. Factors contributing towards bloat in ruminants. J. South African Vet. Med. Assoc. 23(2):103-106.

Clarke D.D. 1991. Fluoroacetate and fluorocitrate: Mechanism of action. Neurochem. Res. 16(9):1055-1058.

Churchill R. 1996. 1080 Sodium fluoroacetate toxicity in dogs: Control and therapy series. PhD. Thesis, University of Sydney, Australia. 846p.

Collicchio-Zuanaze R.C., Sakate M., Schwartz D.S., Trezza E. \& Crocci A.J. 2006. Calcium gluconate and sodium succinate for therapy of sodium fluoroacetate experimental intoxication in cats: Clinical and electro-cardiographic evaluation. Hum. Exp. Toxicol. 25(4):175-182.

Colodel E.M. 1999. Comunicação pessoal (Universidade Federal do Mato Grosso, Cuiabá, MT).

Consorte L.B., Peixoto P.V. \& Tokarnia C.H. 1994. Intoxicação experimental por Pseudocalymma elegans (Bignoniaceae) em ovinos. Pesq. Vet. Bras. 14(4):123-133.

Cook C.J., Eason C.T., Wickstrom M. \& Devine C.D. 2001. Developments of antidotes for sodium monofluoroacetate (1080). Biomarkers 6:72-76.

Cunha L.C. 2008. Avaliação dos efeitos tóxicos de Mascagnia rigida em ratos: 
estudo anatomopatológico, comparação entre metodologias cromatográficas para detecção do fluoroacetato de sódio. Dissertação de Mestrado em Patologia Experimental e Comparada, Universidade de São Paulo, SP. 100p.

Demarchi A.C.C., Menezes M.L., Mercadante A. \& Vassillief I. 2001. Determination of the sodium monofluoroacetate in serum by gas chromatography. Chromatographia 54:402-404.

Döbereiner J. \& Tokarnia C.H. 1959. Intoxicação de bovinos pela "erva-de-rato" (Palicourea marcgravii St. Hil.) no vale do Itapicuru, Maranhão. Arqs Inst. Biol. Anim., Rio de J., 2:83-91.

Döbereiner J. \& Tokarnia C.H. 1982. Intoxicação experimental por Palicourea grandiflora (Rubiaceae) em coelhos. Pesq. Vet. Bras. 2(3):121-124.

Döbereiner J. \& Tokarnia C.H. 1983. Intoxicação experimental por Arrabidaea japurensis (Bignoniaceae) em coelhos. Pesq. Vet. Bras. 3(3):95-97.

Döbereiner J., Tokarnia C.H \& Silva M.F. 1983. Intoxicação por Arrabidaea bilabiata em bovinos na Região Amazônica do Brasil. Pesq. Vet. Bras. 3(1):17-24.

Döbereiner J., Peixoto P.V. \& Tokarnia C.H. 1984. Intoxicação experimental por Arrabidaea bilabiata (Bignoniaceae) em coelhos. Pesq. Vet. Bras. 4(3):89-96.

Döbereiner J., Gava A., Consorte L.B. \& Tokarnia C.H. 1986. Intoxicação experimental por Mascagnia pubiflora (Malpighiaceae) em coelhos. Pesq. Vet. Bras. 6(2):51-57.

Eason C.T. 2002. Sodium monofluoroacetate (1080) risk assessment and risk communication. Toxicology 27:181-182, 523-530.

Eason C.T., Gooneratne R., Fitzgerald H., Wright G. \& Frampton C. 1994. Persistence of sodium monofluoroacetate in livestock animals and risk to humans. Hum. Exp. Toxicol. 13:119-122.

Eastland W.G. \& Beasom S.L. 1986. Effects of ambient temperature on the 1080-LD50 of racoons. Wildl. Soc. Bull. 14:234-235.

Egekeze J.O. \& Oehme F.W. 1979. Inorganic and organic fluoride concentrations in tissues after the oral administration of sodium mono-fluoroacetate (compound 1080) to rats. Toxicology 15:43-53.

Egyed M.N. 1978. Mass poisoning in dogs associated with feeding meat contaminated with organofluoride (sodium fluoroacetate or fluoro-acetamide). Refu. Vet. 35:9-11.

Egyed M.N. \& Schultz R.A. 1986. The efficacy of acetamide for the treatment of experimental Dichapetalum cymosum (gibflaar) poisoning in sheep. Onderst. J. Vet. Res. 54:231-234.

Eisler R. 1995. Sodium monofluoroacetate (1080) hazards to fish, wildlife, and invertebrates: A synoptic review. Biological Report 27, U.S. National Biological Service, Patuxent Environmental Science Centre. 52p.

EPA 1976. Effects of exposure to heavy metals on selected fresh water fish: Toxicity of copper, cadmium, chromium, and lead to eggs and fry of seven fish species. Environmental Research Laboratory, Office of Research and Development, U.S. Environmental Protection Agency, Duluth, 105p.

EPA 1995. Sodium fluoroacetate. Office of Pesticides and Toxic Substances, U.S. Environmental Protection Agency, Washington. 6p.

Fanshier D.W., Gottwald L.K. \& Kun E. 1964. Studies on specific enzyme inhibitors. VI. Characterization and mechanism of action the enzyme inhibitory isomer of monofluorocitrate. J. Biol. Chem. 239:425-434.

Feldwick M.G., Noakes P.S., Prause U., Mead R.J. \& Kostyniak P.J. 1997. The biochemical toxicology of 1,3-difluoro-2-propanol, the major ingredient of the pesticide Gliftor: The potential of 4-methylpyrazole as an antidote. J. Biochem. Mol. Toxicol. 12:41-52.

Foss G.L. 1948. The toxicology and pharmacology of methyl fluoro-acetate (MFA) in animals, with some notes on experimental therapy. Braz. J. Pharmacol. 3:118-127.

Fuyu G., Huifang W. \& Yi L. 1996. Sensitive and selective method for the determination of sodium monofluoroacetate by capillary zone electrophoresis. J. Chromatogr. 719:421-426.

Gajdusek D.C. \& Luther G. 1950. Fluoroacetate poisoning: A review and report of a case. Am. J. Dis. Child. 79:310-320.

Gagnin M.A.H. \& Maravalhas N. 1969. Ocorrência de alcalóides no gênero
Palicourea. Anais do $20^{\circ}$ Congresso Nacional de Botânica, Goiânia, Goiás, p.91-105.

Gava A., Cristani J., Branco J.V., Neves D.S., Mondadori A.J. \& Sousa R.S. 1998. Mortes súbitas em bovinos causadas pela ingestão de Mascagnia sp. (Malpighiaceae), no Estado de Santa Catarina. Pesq. Vet. Bras. 18(1):16-20.

Goh C.S.S., Hodgson D.R., Fearnside S.M., Heller J. \& Malikides N. 2005. Sodium monofluoroacetate (Compound 1080) poisoning in dogs. Aust. Vet. J. 83(8):474-479.

Goncharov N.V., Jenkins R.O. \& Radilov A.S. 2005. Toxicology of fluoroacetate: A review, with possible directions for therapy research. J. Appl. Toxicol. 26(2):148-161.

Górniak S.L., Palermo-Neto J. \& Spinosa H.S. 1993. Effect of CNS depressant drugs on acute intoxication from Palicuorea marcgravii St. Hil. in rats. Vet. Hum. Toxicol. 35:19-21.

Górniak S.L., Palermo-Neto J. \& Spinosa H.S. 1994. Effects of acetamide on experimentally-induced Palicourea marcgravii (St. Hil.) poisoning in rats. Vet. Hum. Toxicol. 36(2):101-102.

Gooneratne S.R., Eason C.T., Dickson C.J., Fitzgerald H. \& Wright G. 1995. Persistence of sodium monofluoroacetate in rabbits and risk to non-target species. Hum. Exp. Toxicol. 14:212-216.

Gribble G.W. 1973. Fluoroacetate toxicity. J. Chem. Educ. 50:460-463.

Grollman A.P., Harrison H.C. \& Harrison H.E. 1961. The renal excretion of citrate. J. Clin. Invest. 40:1290-1296.

Guimarães C.C. 1934. Herva de rato. Vida Med. 2:324-333.

Hatch C.R. 1987. Venenos que provocam estimulação ou depressão nervosa, p.852-892. In: Jones L.M., Booth N.H. \& McDonald L.E. (Eds), Farmacologia e Terapêutica em Veterinária. $4^{\mathrm{a}}$ ed. Guanabara Koogan, Rio de Janeiro.

Helayel M.A., França T.N., Seixas J.N., Nogueira V.A., Caldas S.A. \& Peixoto P.V. 2009. Morte súbita em bovinos causada pela ingestão de Pseudo-calymma elegans (Bignoniaceae) no município de Rio Bonito, RJ. Pesq. Vet. Bras. 29(7):498-508.

Hoogenboom J.J.L. \& Rammell C.G. 1987. Determination of sodium monofluoroacetate (compound 1080) in tissues and baits as its benzyl ester by reaction-capillary gas chromatography. J. Anal. Toxicol. 11:140-143.

Hornfeldt C.S. \& Larson A.A. 1990. Seizures induced by fluoroacetic acid and fluorocitric acid may involve chelation of divalent cations in the spinal cord. Eur. J. Pharmacol. 179:307-313.

Hornshaw T.C., Ringer R.K., Aulerich R.J. \& Casper H.H. 1986. Toxicity of sodium monofluoroacetate (compound 1080) to mink and European ferrets. Environ. Toxicol. Chem. 5:213-223.

Huang T.Y., Pang X.Q. \& Chang H.L. 1980. Prophylactic effect of reserpine in cardiac failure caused by monofluoroacetic acid derivatives. Acta Pharmacol. Toxicol. 47:78-80.

Humphreys D.J. 1988. Veterinary Toxicology. $3^{\text {rd }}$ ed. Bailliere Tindall, London. 356p.

Hutchens J.O., Wagner H. \& Podolsky B. 1949. The effect of ethanol and various metabolites on fluoroacetate poisoning. J. Pharmacol. Exp. Ther. 95:62-70.

Jabour F.F., Seixas J.N., Tokarnia C.H. \& Brito M.F. 2006. Variação da toxidez de Arrabidaea bilabiata (Bignoniaceae) em coelhos. Pesq. Vet. Bras. 26(3):171-176.

Jarret I.G. \& Packham A. 1956. Response of sheep to sublethal doses of fluoroacetate. Nature 177:580-581.

Jensen R., Tobiska J.W. \& Ward J.C. 1948. Sodium fluoroacetate (compound 1080) poisoning in sheep. Am. J. Vet. Res. 9:370-372.

Kimball B.A. \& Mishalanie E.A. 1993. Gas chromatographic determination of sodium monofluoroacetate as the free acid in an aqueous solvent. J. Chromatogr. 634:289-296.

Kirk R.W. 1980. Current Veterinary Therapy. $7^{\text {th }}$ ed. W.B. Saunders, Philadelphia. $110 \mathrm{p}$.

Kramer H.L. 1984. Liquid chromatographic determination of sodium flu- 
oroacetate (compound 1080) in meat baits and formulations. J. Assoc. Anal. Chem. 67(6):1058-1061.

Krebs H.C., Kemmerling W. \& Habermehl G. 1994. Qualitative and quantitative determination of fluoroacetic acid in Arrabidea bilabiata and Palicourea marcgravii by F-NMR spectroscopy. Toxicon 32:909-913.

Lloyd W.E. 1983. Sodium fluoroacetate (compound 1080) poisoning. In: Kirk R.W. (Ed.), Current Veterinary Therapy. $8^{\text {th }}$ ed. W.B. Saunders, Philadelphia, p.112-113.

Marais S.T. 1944. Monofluoroacetic acid, the toxic principle of "Gifblaar" Dichapetalum cymosum (Hook). Onderstepoort J. Vet. Sci. Anim. Ind. 20:67-73.

Marks C.A., Hackman C., Busana F. \& Gigliotti F. 2000. Assuring that 1080 toxicosis in the red fox (Vulpes vulpes) is humane: Fluoroacetic acid (1080) and drug combinations. Wildl. Res. 27:483-494.

Marrazzi M.A. \& Holliday J.F. 1981. Comparison of insulin hypoglycemia-induced and fluoroacetate-induced convulsions in gold thioglucose lesioned mice. Biochem. Pharmacol. 30:3231-3237.

McGary E.D. \& Meloan C.E. 1982. A rapid qualitative method for the detection of monofluoroacetic acid (1080) in the presence of sodium fluoride in liquide baits. Anal. Lett. 15:1051-1056.

McGirr J.L. \& Papworth D.S. 1955. The toxicity of rodenticides. I. Sodium fluoroacetate, Antu and Warfarin. Vet. Rec. 67:124-131.

McEwan T. 1964. Isolation and identification of the principle of Gastrolobium grandiflorum. Queensl. J. Agric. Sci. 21(2):1-14.

McIlroy J.C. 1981. The sensivity of Australian animals to 1080 poison. I. Intraespecific variation and factors affecting acute toxicity. II. Marsupial and eutherian carnivores. Aust. Wildl. Res. 8:369-383, 385-399.

Mcllroy J.C. 1982a. The sensitivity of Australian animals to 1080 poison. III. Marsupial and eutherian herbivores. Aust. Wildl. Res. 9:487-503.

McIlroy J.C. 1982 b. The sensitivity of Australian animals to 1080 poison. IV. Native and introduced rodents. Aust. Wildl. Res. 9:505-517.

McIlroy J.C. 1983a. The sensitivity of Australian animals to 1080 poison. V. The sensitivity of feral pigs, Sus scrofa, to 1080 and its implications for poisoning campaigns. Aust. Wildl. Res. 10:139-148.

Mcllroy J.C. 1983b. The sensitivity of Australian animals to 1080 poison. VI. Bandicoots. Aust. Wildl. Res. 10:507-512.

Mcllroy J.C. 1984. The sensitivity of Australian animals to 1080 poison. VII. Native and introduced birds. Aust. Wildl. Res. 11:373-385.

McIlroy J.C. 1985. The sensitivity of Australian animals to 1080 poison. VIII. Amphibians and reptiles. Aust. Wildl. Res. 12:113-118.

Mcllroy J.C. 1986. The sensitivity of Australian animals to 1080 poison IX. Comparisons between the major groups of animals, and the potential danger non-target species face from 1080-poisoning campaigns. Aust. Wildl. Res. 13:39-48.

McTaggart D.R. 1970. Poisoning due to sodium fluoroacetate (“1080"). Med. J. Aust. 2:641-642.

Mehlman M.A. 1968. Inhibition of pyruvate carboxylation by fluorocitrate in rat kidney mitochondria. J. Biol. Chem. 243(8):1919-1925.

Meldrum G.K. \& Bignell J.T. 1957. The use of sodium fluoroacetate (compound 1080) for the control of the rabbit in Australia. Aust. Vet. J. 33:186-196.

Minnaar P.P., Swan G.E., McCrindle R.I., De beer W.H. \& Naude T.W. 2000. A high-performance liquid chromatographic method for the determination of monofluoroacetate. J. Chromatogr. Sci. 38:16-20.

Misustová J., Novák L. \& Hosek B. 1969. Influence of lowered environmental temperature on metabolic and lethal effects of sodium fluor-acetate in mice. Physiol. Bohemoslov. 18:319-323.

Moraes-Moreau R.L., Haraguchi M., Morita H. \& Palermo-Neto J. 1995. Chemical and biological demonstration of the presence of mono-fluoroacetate in the leaves of Palicourea marcgravii St. Hil. Braz. J. Med. Biol. Res. 28:685-692.

Mount M.E. 1992. Toxicologia, p.482-488. In: Ettinger S.J., Ackerman N. \&
Altman S. (Eds), Tratado de Medicina Interna Veterinária. 3ª ed. Manole, São Paulo.

Nicolella A., Ferreira E.M., Lessa C.A.S., Medeiros M.S.C. \& Lisboa A. 2005. Dados de grupo de agentes, p.69-96. In: Nicolella A., Ferreira E.M., Lessa C.A.S. \& Dallegrave E. (Eds), Toxicovigilância, Toxicologia Clínica. Centro de Informação Toxicológica do Rio Grande do Sul, Porto Alegre.

Nicolella A., Ferreira E.M., Lessa C.A.S. \& Medeiros M.S.C. 2006. Dados de grupo de agentes, p.65-96. In: Nicolella A., Ferreira E.M., Lessa C.A.S. \& Dallegrave E. (Eds), Toxicovigilância, Toxicologia Clínica. Centro de Informação Toxicológica do Rio Grande do Sul, Porto Alegre.

Nicolella A., Ferreira E.M., Lessa C.A.S. \& Medeiros M.S.C. 2007. Dados de grupo de agentes, p.65-96. In: Nicolella A., Ferreira E.M., Lessa C.A.S. \& Dallegrave E. (Eds), Toxicovigilância, Toxicologia Clínica. Centro de Informação Toxicológica do Rio Grande do Sul, Porto Alegre.

Nicolella A., Ferreira E.M., Lessa C.A.S. \& Medeiros M.S.C. 2008/2009. Dados de grupo de agentes, p.67-94. In: Nicolella A., Ferreira E.M., Lessa C.A.S. \& Dallegrave E. (Eds), Toxicovigilância, Toxicologia Clínica. Centro de Informação Toxicológica do Rio Grande do Sul, Porto Alegre.

Nogueira V.A., França T.N., Peixoto T.C., Caldas S.A., Armién A.G. \& Peixoto P.V. 2010. Intoxicação experimental por monofluoroacetato de sódio em bovinos: aspectos clínicos e patológicos. Pesq. Vet. Bras. 30 (7):533-540.

Norris W.R., Eason C.T. \& Wickstrom M.L. 2000. Sorption of fluoroacetate (compound 1080) by colestipol, activated charcoal and anion-exchange resins in vitro and gastrointestinal decontamination in rats. Vet. Hum. Toxicol. 42:269-275.

Novák L., Misustová J. \& Hosek B. 1972. Course of respiratory exchange and body temperature in mice after repeated administration of fluor-acetate: An indicator of aconitase activity in vivo. Physiol. Bohemoslov. 21:53-61.

Oelrichs P.B. \& McEwan T. 1962. The toxic principle of Acacia georginae. Queensl. J. Agric. Sci. 19:1-16.

O’Hagan B.J. 2004. Fluoroacetate poisoning in seven domestic dogs. Aust. Vet. J. 82:756-758.

Oliveira Z. 1955. Sensibilidade dos roedores aos novos rodenticidas Revta Hig. Saúde Públ. 14(1/20):45-56.

Oliveira M.M. 1963. Chromatographic isolation of monofluoroacetic acid from Palicourea marcgravii St. Hil. Experientia 19:586.

Oliveira C.M.C., Barbosa J.D., Macedo R.S.C., Brito M.F., Peixoto P.V. \& Tokarnia C.H. 2004. Estudo comparativo da toxidez de Palicourea juruana (Rubiaceae) para búfalos e bovinos. Pesq. Vet. Bras. 24(1):27-30.

Oliver A.J., King D.R. \& Mead R.J. 1979. Fluoroacetate tolerance, a genetic marker in some Australian mamals. Aust. J. Zool. 27:362-72.

Omara F. \& Sisodia C.S. 1990. Evaluation of potential antidotes for sodium fluoroacetate in mice. Vet. Hum. Toxicol. 32:427-429.

OMS 2001. Fichas técnicas de plaguicidas a prohibir o restringir incluidos en el acuerdo no.9, de La XVI Reunión del Sector Salud de Centro-américa y República Dominicana (Resscad), Costa Rica.

Ortis M. 2005. Comissão externa destinada a acompanhar as investigações sobre o envenenamento de animais ocorrido na Fundação Zoológico de São Paulo (envenenamento no Zoológico de São Paulo). Disponível em <www. camara.gov.br/sileg/integras/292702.pdf> Acesso em 14 ago. 2009.

Osweiler G.D. 1996. Rodenticides, p.289-293. In: Ibid. (Ed.), Toxicology. Willians and Wilkins, Philadelphia

Ozawa H. \& Tsukioka T. 1989. Determination of sodium monofluoro-acetate in soil and biological samples as the dichloroanilide derivative. J. Chromatogr. 473:251-259.

Palermo-Neto J. \& Moraes-Moreau R.L. 1995. Monofluoroacetato de sódio (Composto 1080). Folha Med. 110:59-65.

Palmateer S.D. 1989. Status of strychnine, compound 1080, and registered alternatives. Proc. $9^{\text {th }}$ Great Plains Wildlife Damage Control Workshop, U.S. Department of Agriculture, Forest Service General Technical Report RM-171, p.14-16. (Also published as Great Plains Agricultural Council Publication 127)

Palmateer S.D. 1990. Registration status of vertebrate pesticides with em- 
phasis on 1080 and strychnine. Proc. $14^{\text {th }}$ Vertebrate Pest Conference, University of California, Davis, p.113-115.

Parton K. 2006. Sodium monofluoroacetate (1080), p.1055-1062. In: Ibid. (Ed.), Small Animal Toxicology. W.B. Saunders, Philadelphia.

Pattison F.L. 1959. Toxic Aliphatic Fluorine Compounds. Elsevier Publishing, London. 227p.

Peacock E.A. 1964. Sodium monofluoroacetate (compound 1080). Circular Letter dated 1 July 1964, Division of Predator and Rodent Control U.S. Bureau of Sport Fisheries and Wildlife. 26p. (Mimeographed).

Peixoto P.V., Tokarnia C.H., Döbereiner J. \& Peixoto C.S. 1987. Intoxicação experimental por Palicourea marcgravii (Rubiaceae) em coelhos. Pesq. Vet. Bras. 7(4):117-129.

Peixoto T.C., Nogueira V.A., Coelho C.D., Veiga C.C.P., Peixoto P.V. \& Brito M.F. 2010. Aspectos clínico-patológicos e laboratoriais da intoxicação experimental por monofluoroacetato de sódio em ovinos. Pesq. Vet. Bras. 30(12):1021-1030.

Peixoto T.C., Caldas S.A., Iglesias L., Catunda Junior F.E.A., França T.N. \& Peixoto P.V. 2011a. Efeito protetor da acetamida sobre a intoxicação experimental por monofluoroacetato de sódio e plantas que causam morte súbita em ratos. (Submetido para publicação)

Peixoto T.C., Nogueira V.A., Caldas S.A., França T.N. \& Peixoto P.V. 2011b. Efeito protetor da acetamida em bovinos indica ácido monofluoroacético como princípio tóxico de Palicourea marcgravii. (Submetido para publicação)

Peixoto P.V., Nogueira V.A., França T.N., Peixoto T.C., Döbereiner J. \& Tokarnia C.H. 2011c. Relationship between a peculiar form of hydropic-vacuolar degeneration of the distal convoluted tubules, monofluoroacetate poisoning, and plants that cause "sudden death" in Brazil, p.365-372. In: Riet-Correa F., Pfister J., Schild A.L. \& Wierenga T. (Eds), Poisoning by Plants, Mycotoxins, and related Toxins. CABI, London.

Pereira N.A. \& Pereira S.M.N. 2005. Contribuição ao estudo de plantas tóxicas e seus antagonistas: erva-de-rato, a Rubiaceae, Palicourea marcgravii. Revta Brasil. Farm. 86(3):109-111.

Peters R.A., Spencer H. \& Bidstrup M.D. 1981. Subacute fluoroacetate poisoning. J. Occup. Med. 23(2):112-113.

Proudfoot A.T., Bradberry S.M. \& Vale J.A. 2006. Sodium fluoroacetate poisoning. Toxicol. Rev. 25(4):213-219.

Raabe W.A. 1981. Ammonia and disinhibition in cat motor cortex by ammonium acetate, monofluoroacetate and insulin-induced hypo-glycemia. Brain Res. 210:311-322.

Rammell C.G. \& Livingstone P.G. 1985. Treatment of 1080 poisoning in dogs with glycerol monoacetate. N. Z. Vet. J. 33:149-150.

Reigart J.R., Brueggeman J.L. \& Keil J.E. 1975. Sodium fluoroacetae poisoning. Am. J. Dis. Child. 129:1224-1226.

Robison W.H. 1970. Acute toxicity of sodium monofluroacetate to cattle. J. Wildl. Manage. 34:647-648.

Robinson R.F., Griffith J.R., Wolowich W.F. \& Nahata M.C. 2002. Intoxication with sodium monofluoroacetate (compound 1080). Vet. Hum. Toxicol. 44:93-95.

Rokita S.E. \& Walsh C. 1983. Turnover and inactivation of bacterial citrate lyase with 2-fluorocitrate and 2-hydroxycitrate stereoisomers. Bio-chemistry 22(12):2821-2828.

Rowley I. 1963. The effect on rabbits of repeated sublethal doses of sodium fluoroacetate. Wildl. Res. 8(1):52-55.

Sakai T.F. \& Miyahara T. 1981. Fluorometric determination of mono-fluoroacetic acid. Eisei Kagaku. 27:45-49.

Santos F.C.C., Fischer P. \& Jardim E.C. 1976. Intoxicação experimental em bovinos por "timbó" Mascagnia pubiflora. Anais Esc. Agron. Vet., Goiânia, 1:97-103.

Sayama K. \& Brunetti 0. 1952. The effects of sodium fluoroacetate (1080) on California quail. Calif. Fish Game 38:295-300.

Schnautz J.0. 1949. Sodium fluoroacetate (Compound 1080) poisoning in cattle. J. Am. Vet. Med. Assoc. 114(864):435.

Schultz R.A., Coetzer J.A.W., Kellerman T.S. \& Naudé T.W. 1982. Observations on the clinical, cardiac and histopathological effects of fluoracetate in sheep. Onderstepoort J. Vet. Res. 49:237-245.

Shapira A.R., Titelman U. \& Bursztein S. 1980. Evaluation of the role of ionized calcium in sodium fluoroacetate (1080) poisoning. Toxicol. Appl. Pharmacol. 56:216-220.

Sherley M. 2007. Is sodium fluoroacetate (1080) a humane poison? Animal Welfare 16: 449-459.

Simonnet H., Gauthier C. \& Pellet M. 1980. Effect of acidosis, alkalosis and monofluoroacetate administration on citrate and ATP content of rat renal medulla and papilla. Arch. Int. Physiol. Biochim. 88:69-74.

Sikulová J. \& Novák L. 1970. Body temperature as an indicator of the radioprotective effect of sodium fluoroacetate in mice. Int. J. Radiat. Biol. 17:587-90.

Spencer A.F. \& Lowenstein J.M. 1967. Citrate content of liver and kidney of rat in various metabolic states and in fluoroacetate poisoning. Biochem. J. 103:342-348.

Sporkert F., Pragst R., Hübner S. \& Mills G. 2002. Headspace solid-phase microextraction with 1-prenyldiazomethaneon-fibre derivatisation for analysis of fluoroacetic acid in biological samples. J. Chromatogr. 772:45-51.

Steyn D. 1934. The Toxicology of Plants in South Africa. Central News Agency, South Africa. 631p.

Tavares M.I., Rezende A.M.L. \& Döbereiner J. 1974. Intoxicação experimental por Pseudocalymma elegans em coelhos e cobaias. Pesq. Agropec. Bras. 9:91-94.

Tokarnia C.H. 2010. Comunicação pessoal (Universidade Federal Rural do Rio de Janeiro, Seropédica, RJ)

Tokarnia C.H. \& Döbereiner J. 1973. Intoxicação por Mascagnia pubiflora em bovinos no Estado de Mato Grosso. Pesq. Agropec. Bras., Sér. Vet. 8:61-68.

Tokarnia C.H. \& Döbereiner J. 1981. Intoxicação por Arrabidaea japurensis (Bignoniaceae) em bovinos em Roraima. Pesq. Vet. Bras. 1:7-17.

Tokarnia C.H. \& Döbereiner J. 1982. Intoxicação experimental por Palicourea juruana (Rubiaceae) em bovinos e coelhos. Pesq. Vet. Bras. 2(1):17-20.

Tokarnia C.H. \& Döbereiner J. 1986. Intoxicação por Palicourea marcgravii (Rubiaceae) em bovinos no Brasil. Pesq. Vet. Bras. 6(3):73-78.

Tokarnia C.H. \& Peixoto P.V. 2006. A importância dos acidentes ofídicos como causa de mortes em bovinos no Brasil. Pesq. Vet. Bras. 26(2):55-68.

Tokarnia C.H., Canella C.F.C. \& Döbereiner J. 1961. Intoxicação por um "tingui" (Mascagnia rigida Griseb.) em bovinos no Nordeste do Brasil. Arqs Inst. Biol. Anim., Rio de J., 4:203-215.

Tokarnia C.H., Döbereiner J., Canella C.F.C. \& Guimarães D.J. 1969. Intoxicação experimental por Pseudocalymma elegans (Vell.) Kuhlm em bovinos. Pesq. Agropec. Bras. 4:195-204.

Tokarnia C.H., Döbereiner J. \& Silva M.F. 1981. Intoxicação por Palicourea grandiflora (Rubiaceae) em bovinos no Território de Rondônia. Pesq. Vet. Bras. 1(3):89-94.

Tokarnia C.H., Döbereiner J. \& Couceiro J.M. 1983. Intoxicação por Palicourea aeneofusca (Rubiaceae), a causa de "mortes súbitas" em bovinos na Zona-da-Mata de Pernambuco. Pesq. Vet. Bras. 3(3):75-79.

Tokarnia C.H., Döbereiner J. \& Peixoto P.V. 1985. Intoxicação experimental por Mascagnia aff. rigida (Malpighiaceae) em bovinos no Norte do Espírito Santo. Pesq. Vet. Bras. 5(3):77-91.

Tokarnia C.H., Peixoto P.V. \& Döbereiner J. 1985. Intoxicação experimental por Mascagnia aff. rígida (Malpighiaceae) em coelhos. Pesq. Vet. Bras. 5(3):77-91.

Tokarnia C.H., Peixoto P.V. \& Döbereiner J. 1986. Intoxicação experimental por Palicourea marcgravii (Rubiaceae) em ovinos. Pesq. Vet. Bras. 6(4):121-131.

Tokarnia C.H., Döbereiner J. \& Canela C.F.C. 1987. Intoxicação experimental por Mascagnia rigida (Malpighiaceae) em coelhos. Arqs Inst. Biol. Anim., Rio de J., 75(2):229-233.

Tokarnia C.H., Peixoto P.V. \& Döbereiner J. 1991. Intoxicação experimental 
por Palicourea marcgravii (Rubiaceae) em caprinos. Pesq. Vet. Bras. 11(3/4): 65-70

Tokarnia C.H., Costa E.R., Barbosa J.D., Armién A.G. \& Peixoto P.V. 1993. Intoxicação experimental por Palicourea marcgravii (Rubiaceae) em eqüinos. Pesq. Vet. Bras. 13(3/4):67-72.

Tokarnia C.H., Peixoto P.V., Armién A.G., Barbosa J.D. \& Driemeier D. 1995. Intoxicação experimental por Pseudocalymma elegans (Bignoniaceae) em eqüinos. Pesq. Agropec. Bras. 15(1):35-39.

Tokarnia C.H., Gava A., Brito M.F., Bezerra P.S. \& Oliveira K.D. 1998. Intoxicação experimental em coelhos por Mascagnia sp (Malpighiaceae) procedente do Estado de Santa Catarina. Pesq. Vet. Bras. 18(2):61-64.

Tokarnia C.H., Döbereiner J. \& Peixoto P.V. 2000. Plantas Tóxicas do Brasil. Editora Helianthus, Rio de Janeiro. 310p.

Tokarnia C.H., Barbosa J.D., Oliveira C.M.C., Brito M.F., Oliveira R.B. \& Barbas L.A. 2004. Aspectos epidemiológicos e clínico-patológicos comparados da intoxicação por Arrabidaea bilabiata (Bignoniaceae) em búfalos e bovinos. Pesq. Vet. Bras. 24(2):74-79.

Tourtellote W.W. \& Coon J.M. 1949. Synergistic effect of sodium acetate and ethanol in antagonizing sodium fluoroacetate (1080) poisoning in mice. Fed. Proc. 8:339.

Tourtellotte W.W. \& Coon J.M. 1950. Treatment of fluoroacetate poisoning in mice and dogs. J. Pharmacol. Exp. Therapeut. 101:82-91.
Trabes J., Rason N. \& Avrahami E. 1983. Computed tomography demonstration of brain damage due to acute sodium monofluorcetate poisoning. Clinic. Toxicol. 20:85-92.

Twigg L.E. \& King D.R. 1991. The impact of fluoroacetate-bearing vegetation on native Australian fauna: A review. Oikos 61:412-430.

Vasconcelos J.S., Riet-Correa F., Dantas A.F.M., Medeiros R.M.T., Galiza G.J.N., Oliveira D.M. \& Pessoa A.F.A. 2008. Intoxicação por Mascagnia rigida (Malpighiaceae) em ovinos e caprinos. Pesq. Vet. Bras. 28(10): 521-526.

Vickery B. \& Vickery M.L. 1973. Toxicity for livestock of organofluorine compounds present in Dichapetalum plant species. Vet. Bull. 43(10): 537-542.

Wickstrom M.L., Cook C.J. \& Eason C.T. 1998. Development of antidotes and improved treatment of 1080 toxicosis. Landcare Research New Zealand. 18p.

Xavier F.G., Kogika M.M. \& Spinosa H.S. 2002. Common causes of poisoning in dogs and cats in a Brazilian veterinary teaching hospital from 1998 to 2000. Vet. Hum. Toxicol. 44(1):115-116.

Zeferino M.A., Collicchio-Zuanaze R.C., Menezes M.L. \& Sakate M. 2005. Validação de um método em cromatografia líquida para análise quantitativa do monofluoroacetato de sódio no soro de gatos intoxicados experimentalmente. Revta Bras. Toxicol. 18:172. 